\title{
The RNA-binding protein Mex3B is a coreceptor of Toll- like receptor 3 in innate antiviral response
}

\author{
Yan Yang ${ }^{1}$, Su-Yun Wang ${ }^{1}$, Zhe-Fu Huang ${ }^{1}$, Hong-Mei Zou ${ }^{1}$, Bing-Ru Yan ${ }^{2}$, Wei-Wei Luo ${ }^{2}$, Yan-Yi Wang ${ }^{1}$ \\ ${ }^{1}$ Wuhan Institute of Virology, State Key Laboratory of Virology, Chinese Academy of Sciences, Hubei 430071, China; ${ }^{2}$ Collabo- \\ rative Innovation Center for Viral Immunology, Medical Research Institute, College of Life Sciences, Wuhan University, Hubei \\ 430072, China
}

Recognition of viral dsRNA by Toll-like receptor 3 (TLR3) leads to induction of interferons (IFNs) and proinflammatory cytokines, and innate antiviral response. Here we identified the RNA-binding protein Mex3B as a positive regulator of TLR3-mediated signaling by expression cloning screens. Cells from $M e x 3 b^{-/}$mice exhibited reduced production of IFN- $\beta$ in response to the dsRNA analog poly(I:C) but not infection with RNA viruses. Mex $3 b^{-/-}$mice injected with poly(I:C) was more resistant to poly(I:C)-induced death. Mex3B was associated with TLR3 in the endosomes. It bound to dsRNA and increased the dsRNA-binding activity of TLR3. Mex3B also promoted the proteolytic processing of TLR3, which is critical for its activation. Mutants of Mex3B lacking its RNA-binding activity inhibited TLR3-mediated IFN- $\beta$ induction. These findings suggest that Mex3B acts as a coreceptor of TLR3 in innate antiviral response.

Keywords: TLR3; Mex3B; proteolytic processing; dsRNA-binding activity

Cell Research (2016) 26:288-303. doi:10.1038/cr.2016.16; published online 29 January 2016

\section{Introduction}

Toll-like receptors (TLRs) are a family of type I integral membrane-associated receptors that recognize structurally conserved components of a wide variety of pathogens, leading to induction of innate immune and inflammatory responses [1]. TLRs are distinct in their cellular localization, ligand recognition and utilization of signaling adaptor molecules. Cell surface TLRs respond to bacterial and fungal components, whereas intracellular TLRs recognize nucleic acids from microbes as well as the host. TLRs contain an extracellular domain (ECD) consisting of leucine-rich repeats (LRRs), which are responsible for ligand recognition, a transmembrane domain and a conserved cytoplasmic Toll/IL-1 receptor (TIR) domain for recruitment of downstream TIR domain-containing adaptor proteins [2]. All TLRs

Correspondence: Yan-Yi Wang

Tel/Fax: +86-27-87198095

E-mail: wangyy@wh.iov.cn

Received 11 September 2015; revised 20 November 2015; accepted 13 December 2015; published online 29 January 2016 except TLR3, which signals entirely through TIR domain-containing adaptor inducing interferon- $\beta$ (TRIF), utilize myeloid differentiation primary response gene 88 (MyD88) to activate downstream signaling that leads to the transcription of proinflammatory cytokine and type I interferon (IFN) genes $[1,3,4]$.

TLR3 is a member of the TLR family which recognizes viral dsRNA and is critically involved in innate antiviral response. TLR3 is expressed in a variety of cell types, such as dendritic cells (DCs), macrophages and fibroblasts. TLR3 is specifically localized in intracellular compartments in DCs but localizes both in intracellular compartments and on the plasma membrane in human fibroblasts [5]. Several studies have demonstrated that TLR3 is cleaved in endolysosomes, which is essential for its activation and prevention of recognition of host nucleic acids [6-11]. Interestingly, the cleavage does not dissociate the $\mathrm{N}$ - and $\mathrm{C}$-terminal fragments but results in the formation of a very stable "cleaved/associated" TLR3 that represents the primary form of the signaling receptor [10].

The molecular structure of TLR3-ECD with or without dsRNA has been determined [12-14]. TLR3-ECD is 
in the shape of a solenoid horseshoe formed by 23 LRRs. The nine-amino-acid Loop1 in LRR12 is the cleavage site of TLR3. Structural analysis of the complex containing two TLR3-ECD molecules bound to a 46-bp dsRNA indicates that TLR3 acts as a dimer and binds to dsRNA directly [14].

It has been shown that CD14, scavenger receptor class-A, and clathrin-mediated endocytic pathways participate in cellular uptake of extracellular dsRNA [15-17]. However, how uptaken dsRNA is presented to TLR3 in intracellular compartments is poorly understood. In this study, we found that the RNA-binding protein Mex3B was required for dsRNA-induced, TLR3-mediated activation of antiviral genes, as well as innate immune response in cells and mice. Mex3B was associated with TLR3 in the endosomes and promoted the dsRNA binding and proteolytic processing of TLR3. Our findings suggest that Mex3B acts as a coreceptor of TLR3 in innate immune response.

\section{Results}

Identification of Mex $3 B$ as a positive regulator of TLR3-mediated signaling

To identify potential new proteins involved in TLR3-mediated signaling, we screened a cDNA array containing 352 expression clones of ubiquitin-related proteins by IFN- $\beta$ promoter reporter assays in 293 cells stably expressing TLR3 (293-TLR3) and identified Mex3B as a candidate protein (Supplementary information, Figure S1). Mex3B belongs to a family of four RNA-binding proteins, named Mex3A to Mex3D, which have been suggested to be involved in RNA metabolism $[18,19]$. Mex3B contains two K homology $(\mathrm{KH})$ domains that bind RNA and a RING finger domain. As shown in Figure 1A, overexpression of Mex3B weakly activated the IFN $-\beta$ promoter by itself and promoted poly(I:C)-induced activation of the IFN- $\beta$ promoter in 293 cells, which express low level of TLR3 (Supplementary information, Figure S2A). Remarkably, overexpression of Mex3B and TLR3 together synergistically potentiated poly(I:C)-induced activation of the IFN- $\beta$ promoter in 293 cells (Figure 1A). Consistently, overexpression of Mex3B dramatically potentiated poly(I:C)-induced activation of the IFN $-\beta$ promoter, NF- $\kappa \mathrm{B}$ and ISRE in 293-TLR3 cells (Figure 1B). Quantitative real-time PCR (qPCR) analysis indicated that overexpression of Mex3B potentiated poly(I:C)-induced transcription of endogenous IFNB1, TNFA and IKBA genes in 293-TLR3 cells (Figure 1C). In similar experiments, Mex3B potentiated poly(I:C)-induced activation of the IFN- $\beta$ promoter in HeLa and HCT116 cells (Figure 1D). In addition,
Mex3B had no marked effects on Sendai virus ( $\mathrm{SeV})$ - or transfected cytoplasmic poly(I:C)-induced activation of the IFN- $\beta$ promoter, which signals through the cytoplasmic RNA sensor RIG-I and/or MDA5 (Figure 1E and Supplementary information, Figure S3), as well as PGN/ TLR2-, TNF $\alpha$ - or IL-1 $\beta$-induced activation of NF- $\mathrm{KB}$ (Supplementary information, Figure S4). These results suggest that overexpression of Mex3B specifically potentiates TLR3-mediated signaling.

\section{Mex3B is essential for TLR3-mediated signaling}

We next determined the roles of endogenous Mex3B in TLR3-mediated signaling. We constructed four Mex3B-RNAi plasmids that could inhibit the expression of endogenous Mex3B to various degrees (Figure 1F). Knockdown of Mex3B inhibited poly(I:C)-induced activation of NF- $\kappa B$, ISRE and the IFN- $\beta$ promoter in 293TLR3 cells (Figure 1G). The degrees of inhibition were correlated with the efficiencies of knockdown of Mex3B by each RNAi plasmid. We chose the \#2 Mex3B-RNAi plasmid for the experiments described below, and similar results were obtained with the \#1 Mex3B-RNAi plasmid. qPCR analysis indicated that knockdown of Mex3B inhibited poly(I:C)-induced transcription of endogenous IFNB 1, ISG56 and TNFA genes in 293-TLR3 cells (Figure $1 \mathrm{H})$. Knockdown of Mex3B also inhibited poly(I:C)-induced IRF3 dimerization, and phosphorylation of both TBK1 and IкB $\alpha$, which are hallmarks of activation of poly(I:C)-induced TLR3 signaling (Supplementary information, Figure S5). Consistently, knockdown of Mex3B inhibited poly(I:C)- but not SeV-induced activation of the IFN- $\beta$ promoter in HCT116 cells (Figure 1I). As expected, knockdown of RIG-I markedly inhibited $\mathrm{SeV}$ - but not poly(I:C)-induced activation of the IFN- $\beta$ promoter, whereas knockdown of TRIF markedly inhibited poly(I:C)- but not $\mathrm{SeV}$-induced signaling (Figure 1I). These results suggest that endogenous Mex3B plays an important role in poly(I:C)-induced, TLR3-mediated signaling.

A recent study has shown that Mex3C is involved in RIG-I-dependent signaling pathway by mediating K63linked ubiquitination of RIG-I [20]. Considering the high sequence homology of the Mex3 proteins, we determined whether the other three Mex3 proteins were involved in innate immune response. We constructed RNAi plasmids targeting these Mex3 genes and examined the knockdown efficiencies by qPCR analysis (Supplementary information, Figure S6A). Knockdown of any of the four Mex3 genes had no marked effects on $\mathrm{SeV}$-induced activation of the IFN- $\beta$ promoter, while knockdown of Mex3B but not Mex3A, Mex3C or Mex3D inhibited poly(I:C)-induced activation of the IFN- $\beta$ promoter 
A

293

IFN- $\beta$

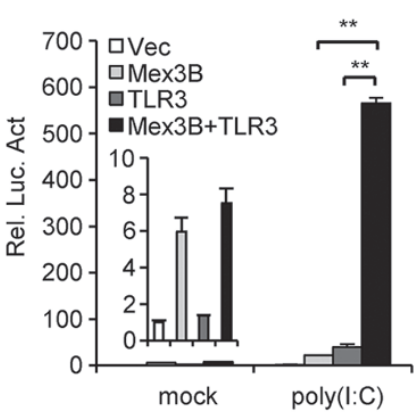

C

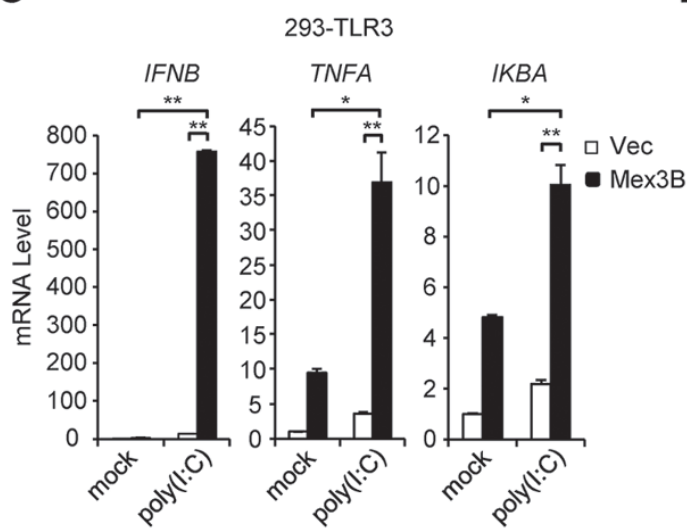

$\mathrm{F}$

G
B

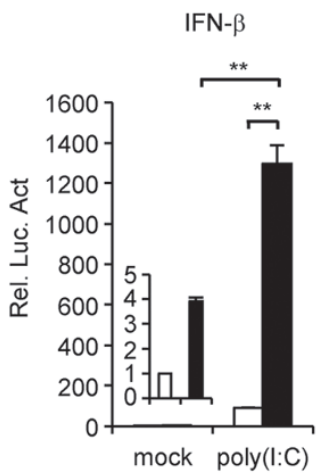

293-TLR3

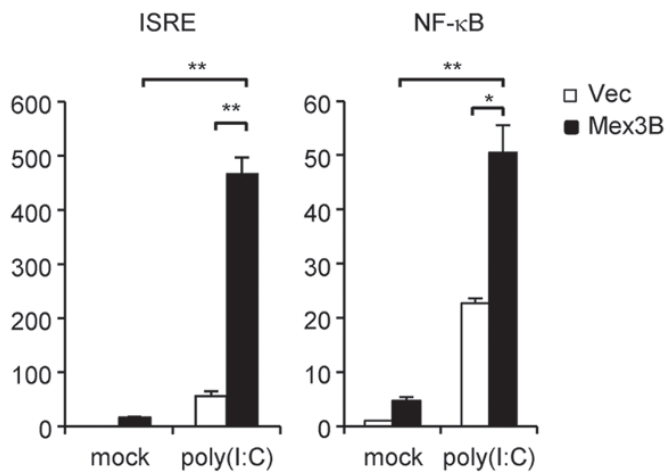

$\mathrm{E}$

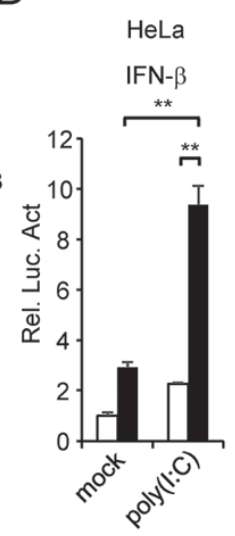

HCT116

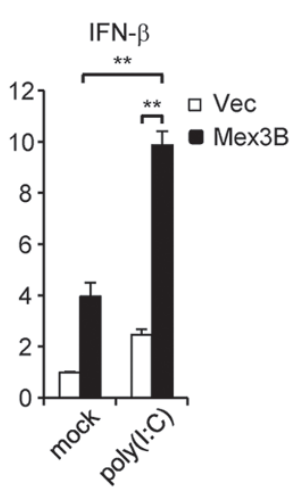

IFN- $\beta$

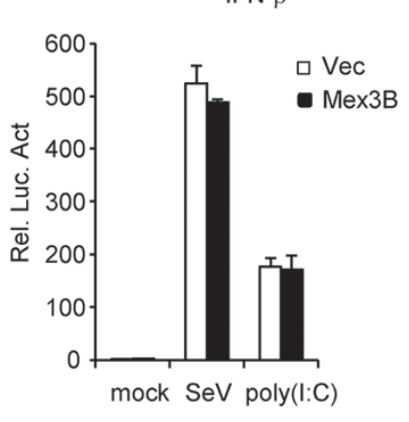

293-TLR3

IFN- $\beta$

ISRE

$\mathrm{NF}-\mathrm{\kappa B}$
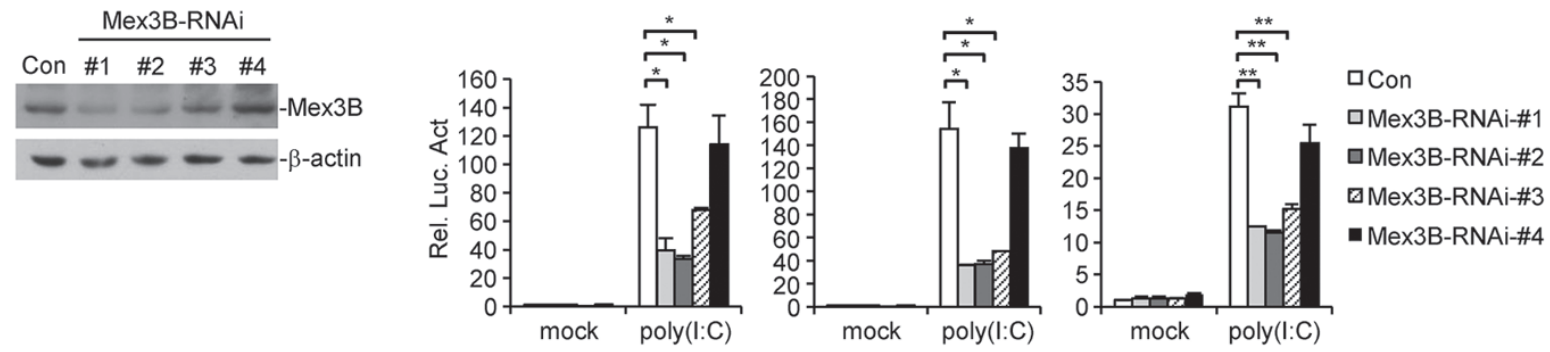

$\mathrm{H}$

293-TLR3

I

HCT116
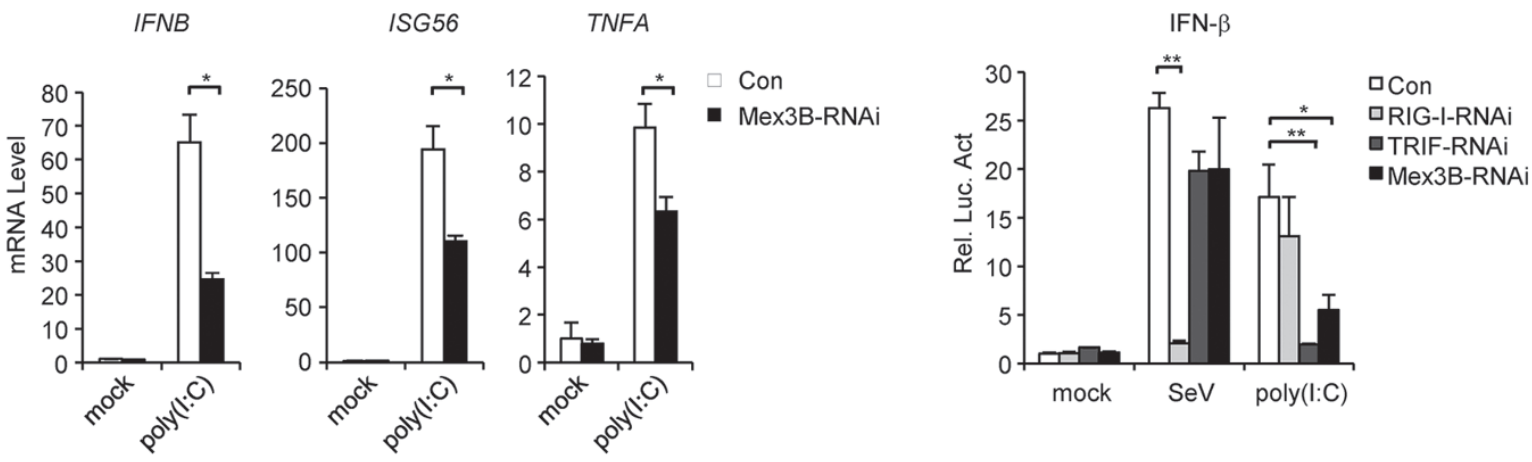
in HCT116 cells (Supplementary information, Figure S6B). These results suggest that only Mex3B among the four Mex3 proteins is involved in poly(I:C)-induced, TLR3-mediated signaling, and none of the four Mex3 proteins is required for $\mathrm{SeV}$-induced signaling.

To further confirm the physiological roles of Mex3B in TLR3-mediated innate immune responses, we generated Mex3b-deficient mice by conventional gene knockout technology (Supplementary information, Figure S7). When $M e \times 3 b^{+/-}$mice were intercrossed, the offspring were born at normal Mendelian ratio, and the $M e x 3 b^{--1}$ mice showed normal growth and development. We examined the expression profile of Mex $3 b$ and $T l r 3$ in mouse tissues by qPCR (Supplementary information, Figure S2B). Both Mex3B and TLR3 had a relatively broad tissue distribution in mouse tissues such as heart, liver, spleen, lung, kidney and small intestine.

To determine whether mouse Mex3B is involved in innate immune responses, we examined expression of downstream genes in wild-type and Mex $3 b$-deficient MEFs in response to various stimuli. We found that poly(I:C)-induced transcription of Ifnbl gene was impaired in Mex3b-deficient MEFs (Figure 2A). In these experiments, $\mathrm{SeV}$ - or vesicular stomatitis virus (VSV)-induced transcription of Ifnbl gene, as well as TNF $\alpha$ - and IL-1 $\beta$-induced transcription of $I k b a$ gene was unaffected in Mex3b-deficient cells in comparison to their wild-type counterparts (Figure 2A). Consistently, Mex3b deficiency also impaired poly(I:C)- but not SeV-induced phosphorylation of IRF3 and IKB $\alpha$ in MEFs (Figure 2B).

To determine the functions of Mex3B in innate immune responses mediated by immune cells, we obtained BMDMs and DCs from wild-type and Mex3b-deficient mice and stimulated these cells with poly(I:C), R837 and PGN (ligands for TLR3, 7 and 2, respectively), or infected the cells with RNA or DNA viruses. We found that
poly(I:C)-induced transcription of Ifnbl gene was significantly impaired in both Mex $3 b$-deficient BMDMs and DCs compared with their wild-type counterparts (Figure $2 \mathrm{C}$ and 2D). Previously, it has been reported that TLR3 is important for innate immune responses against the DNA virus herpes simplex virus 1 (HSV-1) in human $[21,22]$. Interestingly, HSV-1-induced transcription of Ifnbl gene was impaired in Mex $3 b$-deficient BMDMs and DCs. In these experiments, transcription of Ifnbl gene induced by the RNA viruses SeV, VSV and encephalomyocarditis virus (EMCV), as well as transcription of Tnfa gene induced by R837 and PGN were unaffected by Mex3b deficiency (Figure 2C and 2D). These results suggest that deficiency of Mex3B specifically impairs TLR3-mediated signaling in all examined cell types.

\section{Mex $3 b^{-/}$mice are resistant to poly(I:C)-induced death}

To investigate the roles of Mex3B in regulating TLR3-mediated innate immune responses in vivo, we monitored poly(I:C)-induced production of IFN- $\beta$, proinflammatory cytokines TNF $\alpha$ and IL-6, as well as poly(I:C)-induced inflammatory death of wild-type and $M e x 3 b$-deficient mice. Age- and sex-matched wild-type and $M e x 3 b$-deficient mice were injected with poly(I:C) through intraperitoneal (i.p.) route. The induced cytokines in the serum were measured $2 \mathrm{~h}$ after injection, and the survived animals were recorded every $12 \mathrm{~h}$. As shown in Figure 3A, the levels of IFN- $\beta$, TNF $\alpha$ and IL-6 induced by poly $(\mathrm{I}: \mathrm{C})$ were significantly lower in the sera from $M e x 3 b$-deficient mice compared with their wildtype counterparts. Consistently, death of $\mathrm{Mex}_{3} b^{-1-}$ mice induced by injection of poly(I:C) plus D-galactosamine was delayed and reduced in comparison with $M e x 3 b^{+/+}$ mice (Figure 3B). These results suggest that Mex3B plays an essential role in regulating TLR3-mediated production of IFN- $\beta$ and proinflammatory cytokines, as

Figure 1 Mex3B is a positive regulator of TLR3-mediated signaling. (A) Mex3B potentiates TLR3-mediated signaling in 293 cells. The cells were transfected with the indicated plasmids for $24 \mathrm{~h}$, and then treated with poly(l:C) for $6 \mathrm{~h}$ before luciferase assays. (B) Mex3B potentiates poly(I:C)-induced signaling in 293-TLR3 cells. Reporter assays were similarly performed as in A. (C) Mex3B potentiates poly(l:C)-induced expression of downstream genes in 293-TLR3 cells. The cells were transfected with the indicated plasmids for $24 \mathrm{~h}$, and then treated with poly(l:C) for $3 \mathrm{~h}$ before qPCR analysis. (D) Mex3B potentiates poly(I:C)-induced activation of the IFN- $\beta$ promoter in HeLa and HCT116 cells. Reporter assays were similarly performed as in A. (E) Overexpression of Mex3B has no marked effects on SeV- or cytoplasmic poly(I:C)-induced activation of the IFN- $\beta$ promoter. The 293 cells were transfected with the indicated plasmids for $24 \mathrm{~h}$, and then infected with SeV or re-transfected with poly(l:C) for $12 \mathrm{~h}$ before luciferase assays. (F) Effects of Mex3B-RNAi on expression of Mex3B. The 293 cells were transfected with a Mex3B-RNAi plasmid for $24 \mathrm{~h}$ before immunoblot analysis. (G) Effects of Mex3B-RNAi on TLR3-mediated signaling. Reporter assays were similarly performed as in A. (H) Effects of Mex3B-RNAi on poly(I:C)-induced transcription of IFNB1, ISG56 and TNFA genes. The experiments were similarly performed as in C. (I) Effects of Mex3B-RNAi on poly(I:C)and SeV-induced activation of the IFN- $\beta$ promoter in HCT116 cells. The cells were transfected with the indicated plasmids for $24 \mathrm{~h}$, and then infected with $\mathrm{SeV}$ for $12 \mathrm{~h}$ or treated with poly $(\mathrm{I}: \mathrm{C})$ for $6 \mathrm{~h}$ before luciferase assays. Data are represented as mean \pm SEM. ${ }^{*} P<0.05,{ }^{* *} P<0.01$ (Student's $t$-test). 
A

MEF
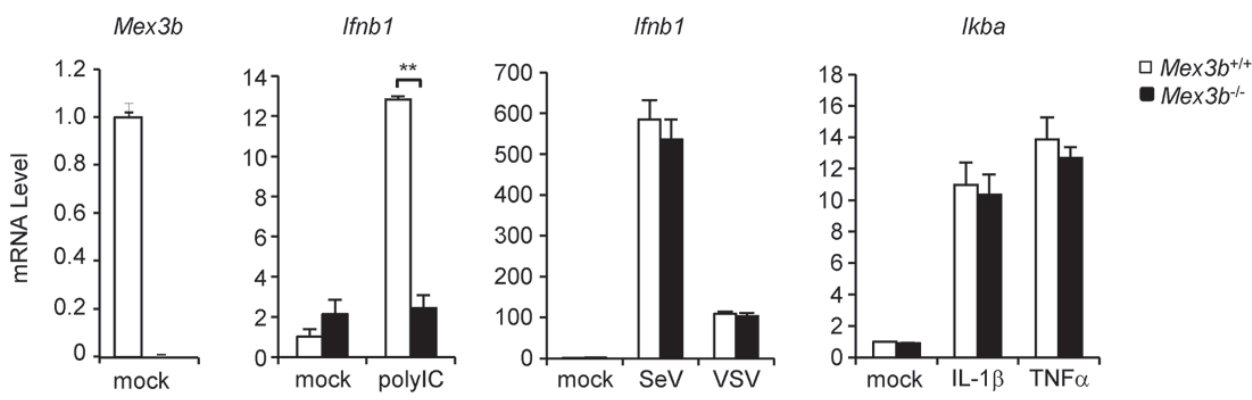

B
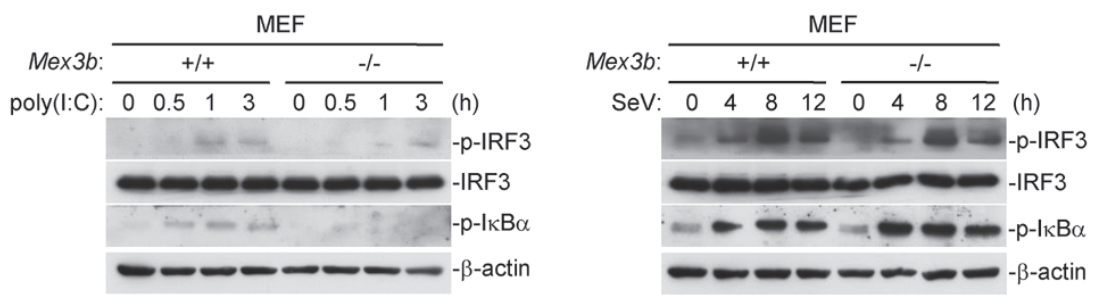

C

BMDM
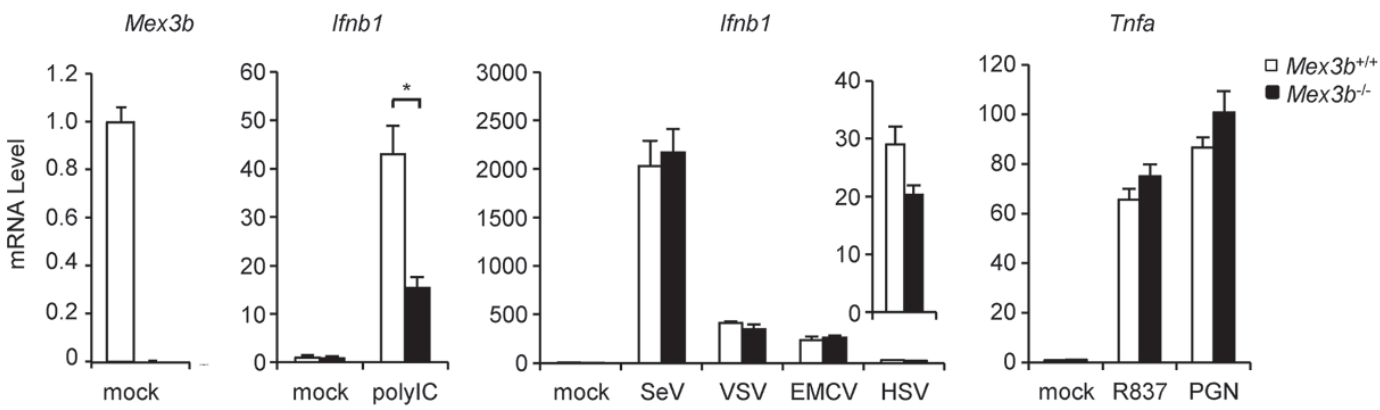

D
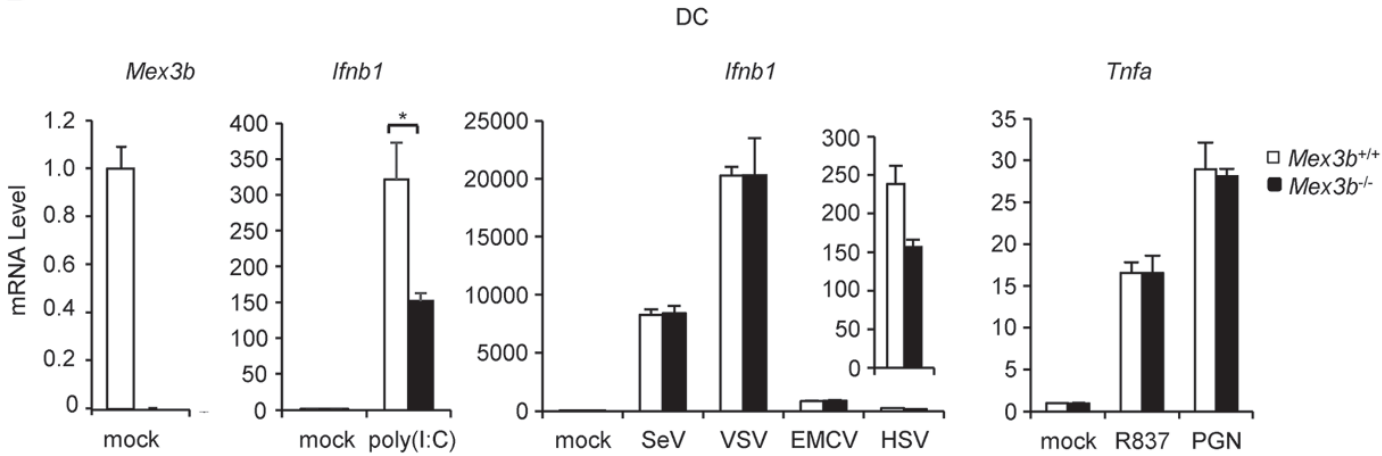

Figure 2 Mex3B is essential for TLR3-mediated signaling in MEFs, BMDMs and DCs. (A) Mex3B deficiency inhibits poly(l:C)-induced transcription of Ifnb1 gene in MEFs. MEFs $\left(2 \times 10^{5}\right)$ were left untreated, treated with poly(l:C) $(20 \mu \mathrm{g} / \mathrm{ml})$, TNF $\alpha(10 \mathrm{ng} / \mathrm{ml})$ or IL-1 $\beta(10 \mathrm{ng} / \mathrm{ml})$ for $3 \mathrm{~h}$, or infected with SeV or VSV for $12 \mathrm{~h}$. Total RNA was then extracted for qPCR analysis. (B) Effects of Mex3B deficiency on poly(I:C)-induced phosphorylation of IRF3 and IKB $\alpha$ in MEFs. MEFs $\left(2 \times 10^{5}\right)$ were left untreated, infected with $\mathrm{SeV}$ or treated with poly $(\mathrm{l}: \mathrm{C})$ for the indicated times. Cells were lysed and immunoblot was performed with the indicated antibodies. (C, D) Mex3B deficiency inhibits poly(I:C)-induced transcription of Ifnb1 gene in BMDMs (C) and DCs (D). The cells $\left(2 \times 10^{5}\right)$ were left untreated, treated with poly(l:C) $(20 \mu \mathrm{g} / \mathrm{ml}), \mathrm{R} 837(20 \mu \mathrm{g} / \mathrm{ml})$ or PGN $(10 \mu \mathrm{g} / \mathrm{ml})$ for $3 \mathrm{~h}$ or infected with SeV, VSV, EMCV or HSV for $12 \mathrm{~h}$ before $\mathrm{qPCR}$ analysis. Data are represented as mean \pm SEM. ${ }^{*} P<0.05,{ }^{* *} P<0.01$ (Student's $t$-test). 
well as inflammatory death. Since genetic studies have suggested that TLR3 is important for innate immune responses against HSV-1 [21, 22], we further investigated the role of Mex3B in host defense against HSV infection in vivo. As shown in Figure 3C, the serum levels of IFN- $\beta$ and proinflammatory cytokines in response to HSV-1 infection slightly decreased in $M e \times 3 b^{-/-}$mice, but such decrease was not statistically significant compared to that of the $M e x 3 b^{+/+}$mice.

\section{Mex3B regulates poly(I:C)-triggered signaling through TLR3}

Mex3B is an RNA-binding protein with two tandem $\mathrm{KH}$ domains in its $\mathrm{N}$-terminal region and a $\mathrm{C}$-terminal RING-finger domain. Previous studies suggest that the adaptor protein 14-3-3 binds to serine 462-phosphorylated Mex3B to stabilize Mex3B and regulates its localization to stress granules (SGs) and processing bodies (PBs) [23]. To determine which domain of Mex3B is responsible for potentiating TLR3 signaling, we constructed a series of truncation and point mutants of Mex3B (Figure 4A). In reporter assays, Mex3B(222-569), which contains the C-terminal RING-finger domain but lacks the two $\mathrm{KH}$ domains, failed to enhance poly(I:C)-triggered, TLR3-mediated activation of the IFN- $\beta$ promoter (Figure 4B). In contrast, Mex3B(1-517), which contains the two RNA-binding $\mathrm{KH}$ domains and the linker region but lacks the RING finger domain, potentiated poly(I:C)-triggered, TLR3-mediated activation of the IFN- $\beta$ promoter to a similar degree to the wild-type Mex3B (Figure 4B). In these experiments, Mex3B(1-236), which only contains the two KH domains, also potentiated poly(I:C)-triggered signaling though to a lower degree compared to the wild-type Mex3B (Figure 4B). Previously, it has been demonstrated that the two residues G83 and G177 in the two respective $\mathrm{KH}$ domains are required for the RNA-binding activity of Mex3B, whereas phosphorylated S462 is a critical residue for 14-3-3 docking and localization of Mex3B to SGs and PBs [23]. Consistent with the data obtained from the truncation mutants, Mex3B(G83/177D), in which G83 and G177 are mutated to aspartic acid, respectively, markedly inhibited poly(I:C)-triggered, TLR3-mediated activation of the IFN- $\beta$ promoter (Figure $4 \mathrm{C}$ ). In contrast, Mex3B(S462A), in which S462 is mutated to alanine, did not have significant effects on poly(I:C)-triggered, TLR3-mediated activation of the IFN- promoter (Figure $4 C)$. These results suggest that the RNA-binding activity of Mex3B is indispensable for its ability to potentiate TLR3-mediated signaling, and that the localization of Mex3B to SGs or PBs is not required for its roles in TLR3-mediated signaling.
It has been reported that TLR 3 is proteolytically cleaved between residues A342 and S343 into two fragments in the endosomes, a process required for its activation [11]. To determine whether the cleavage of TLR3 is required for the potentiation of TLR3-mediated signaling by Mex3B, we generated three mutants of TLR3. TLR3 $\Delta 9$, in which aa335-aa343 in the Loop1 of LRR12 is deleted, was uncleavable (Figure 4A). In reporter assays, TLR $3 \Delta 9$, as well as the two cleaved fragments, TLR3(1-343) and TLR3(343-904), had no or much decreased abilities to amplify poly(I:C)-induced signaling or to synergize with Mex3B to potentiate poly(I:C)-induced activation of the IFN- $\beta$ promoter (Figure 4D). TLR3(1-343) and TLR3(343-904), which either lacks the transmembrane domain or the signal leader of TLR3, may not be in the same cellular compartments where they could associate with each other to initiate signaling. Therefore, cotransfection of these two fragments could not mimic the cleavage of TLR3. These data suggest that TLR3 cleavage is important for the potentiation of its signaling by Mex3B.

To further establish that Mex3B regulates poly (I:C)-triggered TLR3 signaling through TLR3, we determined the effects of dominant-negative mutants of TLR3 and Mex3B on poly(I:C)-induced signaling. As shown in Figure 5A, overexpression of $\mathrm{Mex} 3 \mathrm{~B}(\mathrm{G} 83 / 177 \mathrm{D})$ inhibited poly(I:C)-induced but not TRIF- or TBK1-mediated activation of the IFN- $\beta$ promoter in a dose-dependent manner. In similar experiments, overexpression of a dominant-negative mutant of TLR3, TLR3(C95/122A), which lost the ligand recognition activity [24], inhibited poly(I:C)-induced, TLR3/Mex3B-mediated activation of the IFN- $\beta$ promoter (Figure 5B). In addition, knockdown of Mex3B inhibited poly(I:C)-induced but not TRIF- or TBK1-mediated activation of the IFN- $\beta$ promoter (Figure 5C). These results suggest that TLR 3 and Mex3B are reciprocally required for poly(I:C)-induced signaling.

To determine whether the roles of Mex3B in TLR3-mediated signaling require acidic endosomes, we examined the effects of chloroquine, an inhibitor of endosomal acidification, on Mex3B-mediated effects. As shown in Figure 5D, treatment of cells with chloroquine markedly reduced poly(I:C)-induced, Mex3B/TLR3-mediated activation of the IFN- $\beta$ promoter. These results suggest that Mex3B and TLR3 act in an acidic endosomal-dependent process.

Mex3B is associated with TLR3 and facilitates the recruitment of TRIF upon poly(I:C) stimulation

As Mex3B acts through TLR3, we determined whether they are physically associated with each other. Endogenous coimmunoprecipitation experiments showed that 
A

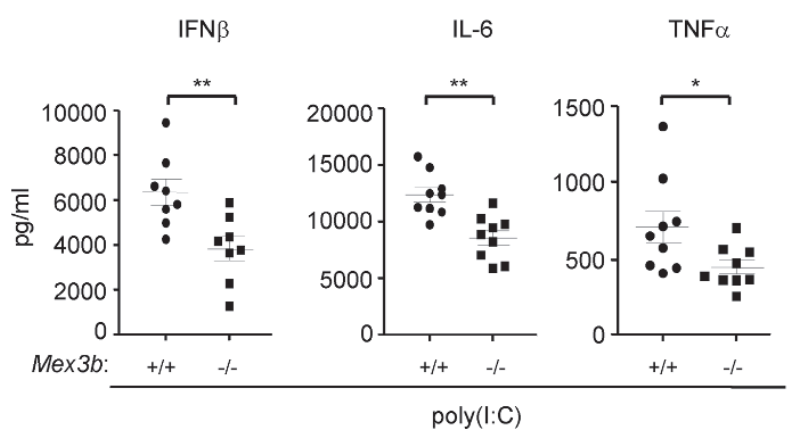

B

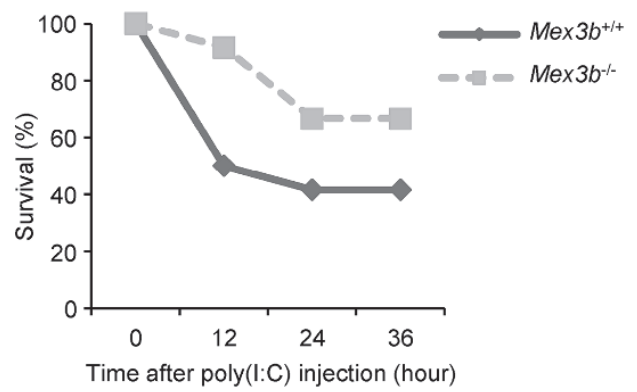

C

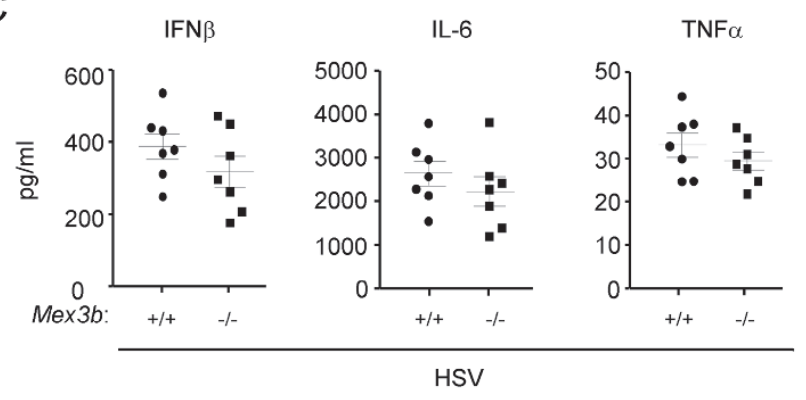

Figure $3 \mathrm{Mex}_{3 \mathrm{~b}^{-/-}}$mice are resistant to poly(I:C)-induced death. (A) Sex- and age-matched Mex $3 b^{+/+}$and Mex $3 b^{-1-}$ mice $(n=8$ or 9 ) were injected intraperitoneally with poly(I:C) for $2 \mathrm{~h}$. Serum concentrations of the indicated cytokines were measured by ELISA. Data are represented as mean \pm SEM. ${ }^{*} P<0.05,{ }^{* *} P$ $<0.01$ (Student's $t$-test). (B) Sex- and age-matched Mex $3 b^{+/+}$ and $M e x 3 b^{-1-}$ mice $(n=12)$ were injected intraperitoneally with poly(I:C) plus D-galactosamine. The survival of injected mice was monitored every $12 \mathrm{~h}$ for 4 days. (C) Mex $3 b^{+/+}$and Mex $3 b^{-1-}$ mice were infected i.p. with HSV-1 at $1 \times 10^{7}$ p.f.u. per mouse $(n=7)$ for $6 \mathrm{~h}$. Serum concentrations of the indicated cytokines were measured by ELISA.

Mex3B was associated with TLR3 under physiological condition and the association was reduced following poly(I:C) stimulation in HCT116 cells and DCs (Figure 6A). Domain mapping experiments indicated that the linker region (aa222-517) of Mex3B and the ectodomain of TLR3 were required for their interaction (Figure 6B). TRIF is a key adaptor in TLR3-mediated activation of $\mathrm{NF}-\kappa \mathrm{B}$ and IRF3. Endogenous coimmunoprecipitation experiments indicated that TRIF was associated with Mex3B in a poly(I:C)-dependent manner (Figure 6C). It has been demonstrated that dimerized TLR3 recruits TRIF upon poly(I:C) stimulation. Knockdown of Mex3B also inhibited poly(I:C)-induced recruitment of TRIF to TLR3 (Supplementary information, Figure S8). These results suggest that Mex3B is associated with TLR3 and facilitates the recruitment of TRIF upon poly(I:C) stimulation.

Mex $3 B$ colocalizes with TLR 3 in acidic vesicles and $f a-$ cilitates the binding of TLR 3 to dsRNA

It has been shown that upon dsRNA stimulation TLR3 translocates to the endolysosomes where it encounters the internalized dsRNA and triggers downstream signaling [25]. We observed that ectopically expressed TLR3 was localized mostly in the endoplasmic reticulum (ER) and transferred to endolysosomes in response to poly(I:C) by immunofluorescence confocal microscopy (Supplementary information, Figure S9A). Unexpectedly, Mex3B colocalized extensively with early endosomes but not with ER or lysosomes in 293 cells (Supplementary information, Figure S9B). When 293 cells were co-transfected with Mex3B and TLR3, Mex3B-positive compartments merged well with TLR3 in the early endosomes (Figure 7A). As ligand binding and signaling of TLR3 take place on different sides of the endosomal membrane, to further elucidate the role of Mex3B in TLR3-mediated signaling, we investigated whether Mex3B localizes to the cytosolic or luminal side of endosomes by proteinase $\mathrm{K}$ protection assay. The results showed that a proportion of Mex3B was resistant to proteinase $\mathrm{K}$ degradation. Interestingly, the accumulation was diminished upon Triton $\mathrm{X}-100$ treatment that permeabilizes membranes (Figure 7B). Domain mapping experiments also indicated that Mex3B was associated with the ectodomain of TLR3 (Figure 6B). These data indicated that Mex3B and TLR3 colocalize in the lumen of endosomes.

Previous studies have indicated that Mex3B is an RNA-binding protein, and our results suggest that the RNA-binding activity of Mex3B is indispensable for potentiating TLR3-mediated signaling (Figure 4B and $4 \mathrm{C})$. We next investigated whether Mex3B affects the dsRNA-binding activity of TLR3. Because the "cleaved/ associated" TLR3 represents the primary form of receptor that recognizes dsRNA, we first determined whether Mex3B affected the proteolytic processing of TLR3. As shown in Figure $7 \mathrm{C}$, overexpression of Mex3B reduced 
A
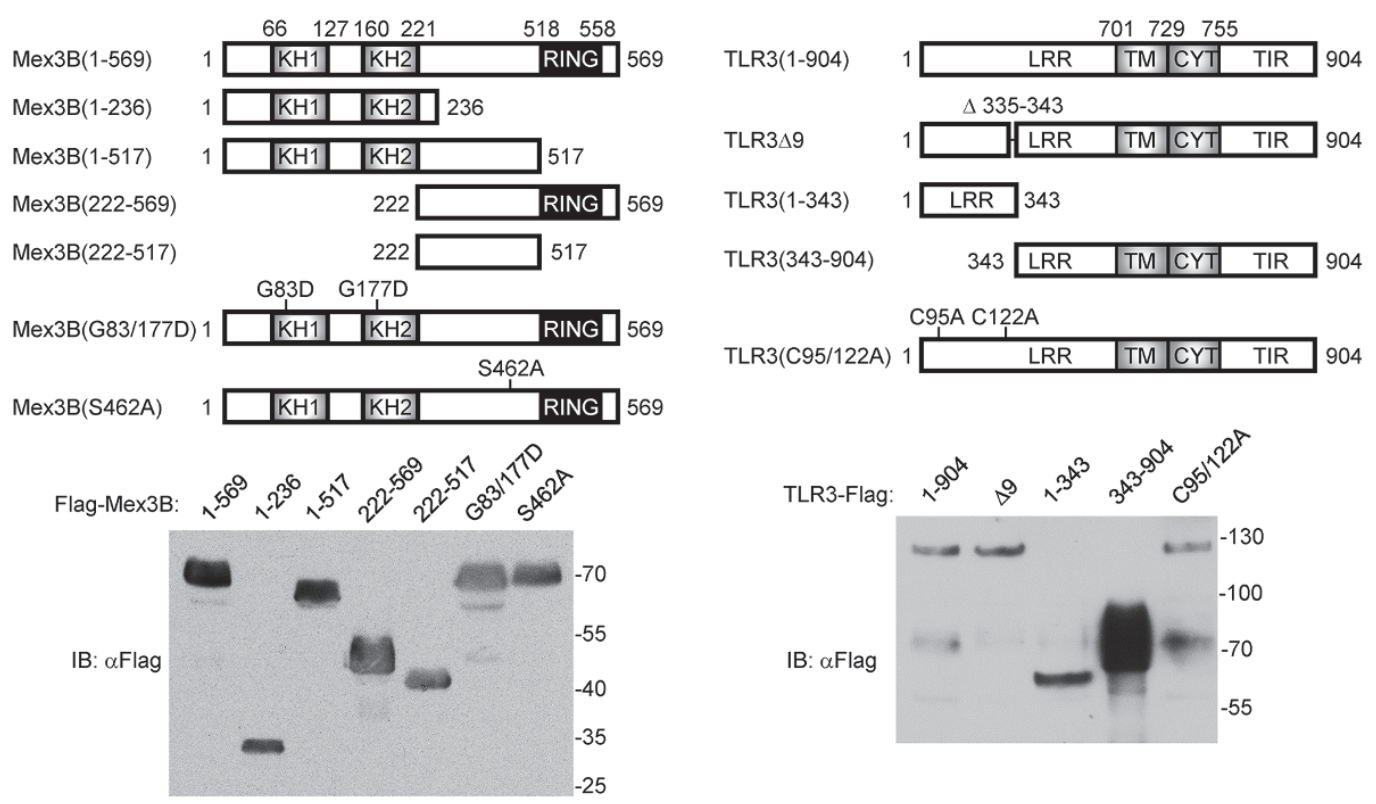

B

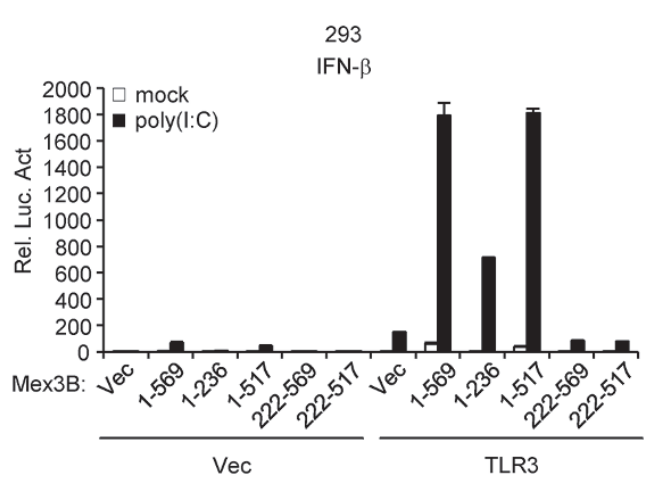

C

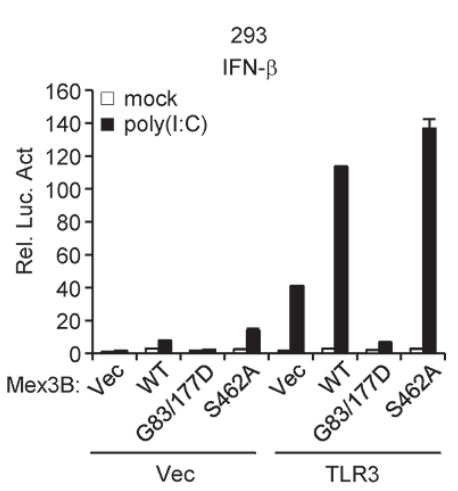

D

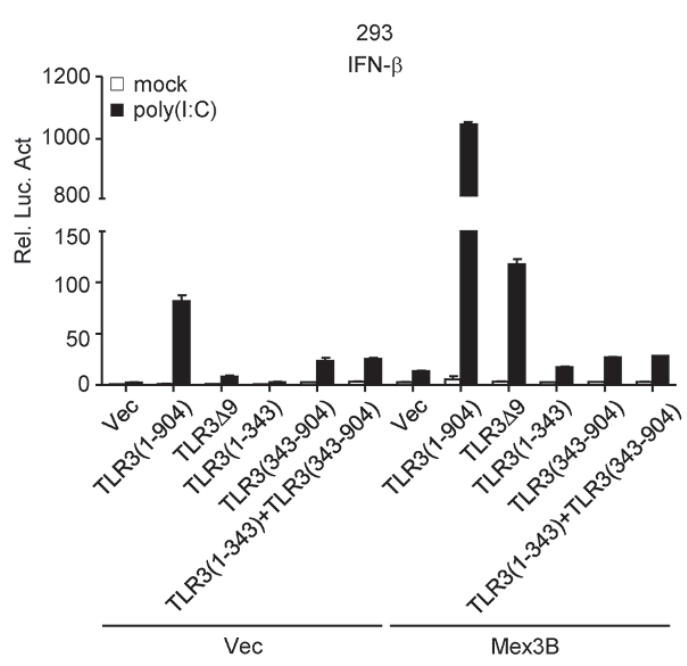

Figure 4 The RNA-binding activity of Mex3B and proteolytic cleavage of TLR3 are indispensable for Mex3B to potentiate TLR3-mediated signaling. (A) A schematic presentation and expression of full-length Mex3B, TLR3 and their mutants. (B-D) Effects of Mex3B mutants on TLR3-mediated signaling. The 293 cells $\left(1 \times 10^{5}\right)$ were transfected with the IFN- $\beta$ promoter reporter $(0.1 \mu \mathrm{g})$ and the indicated plasmids $(0.1 \mu \mathrm{g})$ for $24 \mathrm{~h}$, and then left untreated or treated with poly $(\mathrm{l}: \mathrm{C})(20 \mu \mathrm{g} / \mathrm{ml})$ for $6 \mathrm{~h}$ before luciferase assays. 
the levels of highly glycosylated full-length TLR3 ( 130 $\mathrm{KD})$ and newly synthesized nonglycosylated full-length TLR3 ( $95 \mathrm{KD})$, and simultaneously increased the abundance of processed C-terminal fragment of TLR3, indicating that Mex3B facilitated the processing of TLR3. In these experiments, poly(I:C) stimulation increased TLR3 processing 30 min post stimulation, which was then gradually reduced to normal level. We also examined the effect of Mex3B(G83/177D), a mutant which lost the RNA-binding activity, on the processing of TLR3. The results showed that $\operatorname{Mex} 3 \mathrm{~B}(\mathrm{G} 83 / 177 \mathrm{D})$ potentiated TLR3 processing to a similar degree to that of the wildtype Mex3B (Supplementary information, Figure S10). Notably, knockdown of Mex3B resulted in downregulation of all three forms of TLR3 (Figure 7D). It has been reported that the proteolytic fragments of TLR3 are more stable than its full-length form $[8,10]$. These data suggest that Mex3B stabilizes TLR3 and promotes its processing.

As Mex3B is an RNA-binding protein, we determined whether Mex3B modulates the dsRNA-binding activity of TLR3. Poly(I:C) pull-down assays showed that both the wild-type Mex3B and Mex3B(1-236) could bind to poly(I:C) and enhanced the binding of TLR3 to poly(I:C), while Mex3B(G83/177D) could not bind to poly(I:C) and inhibited the binding of TLR3 to poly(I:C) (Figure 7E). Interestingly, although Mex3B(1-236) was not associated with TLR3 (Figure 6B), coimmunoprecipitation experiments showed that $\mathrm{Mex} 3 \mathrm{~B}(1-236)$ was associated with the full-length Mex3B, which had the ability to interact with TLR3 (Supplementary information, Figure S11). It is possible that Mex3B(1-236) recruited endogenous Mex3B to enhance the ligand binding of TLR3. Taken together, these data suggest that Mex3B facilitates the ligand binding of TLR3. Interestingly, we found that Mex3B(G83/177D), a mutant that potentiated TLR3 processing but completely lost its ability to enhance the ligand binding of TLR3, failed to potentiate TLR3-mediated signaling, which indicates that the RNA-binding activity of Mex3B and its facilitation of the ligand binding of TLR 3 is essential for its function as a coreceptor.

\section{Discussion}

TLR3 is an endosomal TLR that recognizes viral dsRNA, leading to the production of type I IFNs and proinflammatory cytokines. In this study, we identified Mex3B as a critical component of TLR3-mediated innate immune and inflammatory responses. Overexpression of Mex3B markedly potentiated poly(I:C)-induced, TLR3-mediated activation of NF- $\kappa B$, ISRE and the
IFN- $\beta$ promoter, whereas knockdown of Mex3B had opposite effects. Mex $3 b^{-/-}$MEFs, BMDMs and DCs exhibited reduced production of IFN- $\beta$ after poly(I:C) treatment in comparison with their $M e x 3 b^{+/+}$counterparts. In addition, $M e \times 3 b^{-1-}$ mice produced lower levels of serum IFN- $\beta, T N F \alpha$ and IL- 6 after poly(I:C) administration and were more resistant to poly(I:C)-induced death than their wild-type counterparts. Collectively, these results suggest that Mex3B has an important role in TLR3-mediated innate immune and inflammatory responses in vitro and in vivo. In our experiments, Mex $3 b$ deficiency did not affect the transcription of Ifnblor Tnfa genes induced by infection with RNA viruses, such as SeV, VSV and EMCV, or stimulation with PGN and R837, suggesting that Mex3B is not involved in innate immune responses mediated by the intracellular viral RNA sensors RIG-I and/or MDA5, as well as TLR2 and TLR7.

Although it has been well established that TLR3 recognizes viral dsRNA, several reports suggest that TLR3 plays a critical role in natural immunity to the DNA virus HSV-1 infection in the central nervous system in humans. Children with autosomal dominant TLR3 deficiency have a predisposition for HSV-1-induced encephalitis $[21,22]$. Recently, it has been reported that IFN- $\beta$ induction by HSV-1 infection is severely but not completely abolished in $c G A S$ - or Sting-deficient BMDMs and DCs [26]. It is possible that the dsRNA generated during HSV-1 replication might be recognized by TLR3. In this study, we found that HSV-1-induced IFN- $\beta$ production in $M e x 3 b^{-/-}$cells was decreased compared with the wildtype cells. However, this difference was not significant. Consistently, the serum levels of IFN- $\beta$ and proinflammatory cytokines in response to HSV-1 infection were slightly decreased in $M e x 3 b^{-/-}$mice, but such decrease was not statistically significant compared with $M e x 3 b^{+/+}$ mice. The simplest explanation is that TLR3-Mex3B might participate in the recognition of dsRNA generated during HSV-1 replication, however, HSV-1-triggered production of proinflammatory cytokines and interferons may be mostly controlled by the viral DNA sensors but not the TLR3-Mex3B axis.

MEX-3 was initially characterized in Caenorhabditis elegans as a translation repressor that specifies posterior blastomere identity during early embryogenesis and has an essential role in maintaining the germline totipotency in adults [27]. Among the four human Mex3 proteins, Mex3A may function as the ortholog of the $C$. elegans Mex-3. It has been reported that Mex3A downregulates the intestinal transcription factor CDX2 during vertebrate embryonic development [28]. Recently, it has been reported that Mex3B orchestrates Sertili cell function by regulating the Rap1 pathway, which may account for the 
A

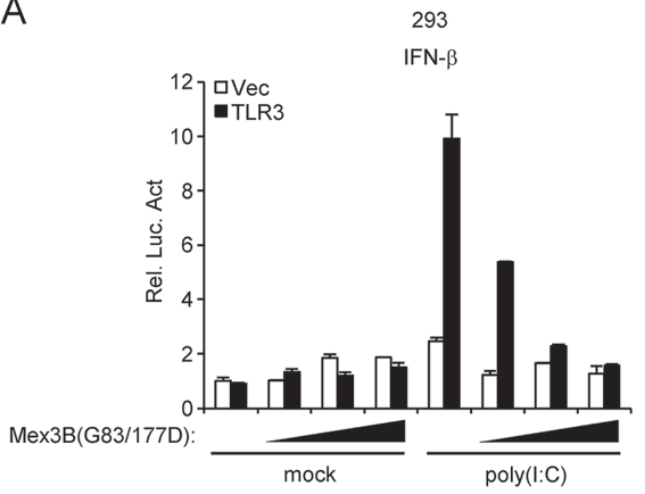

B

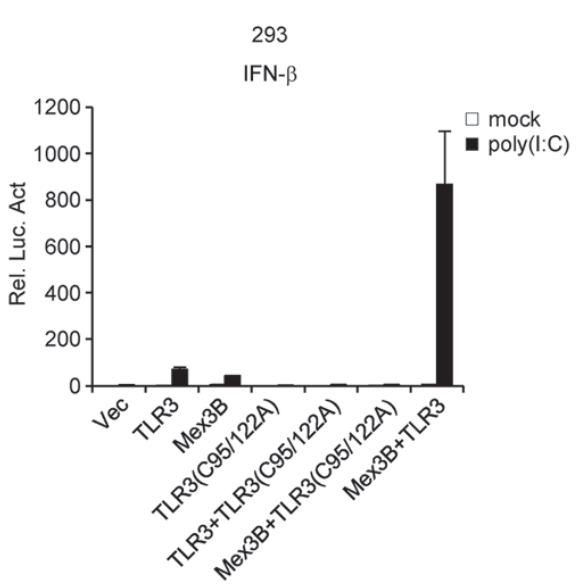

D
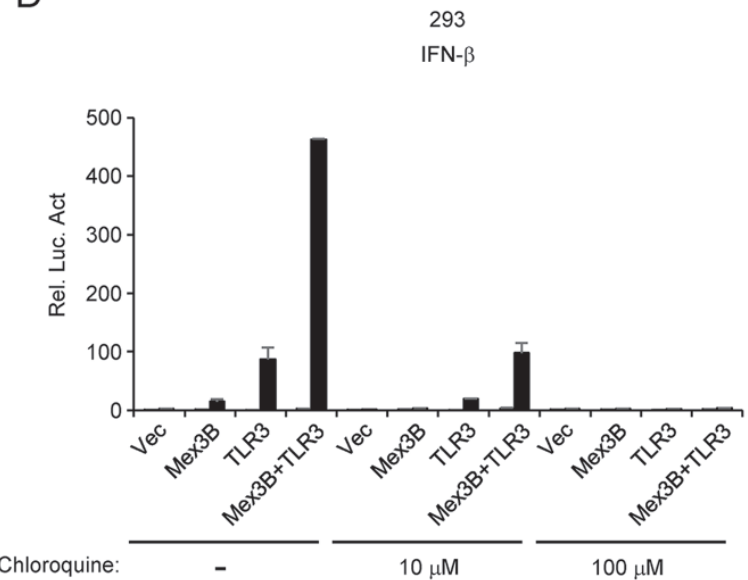

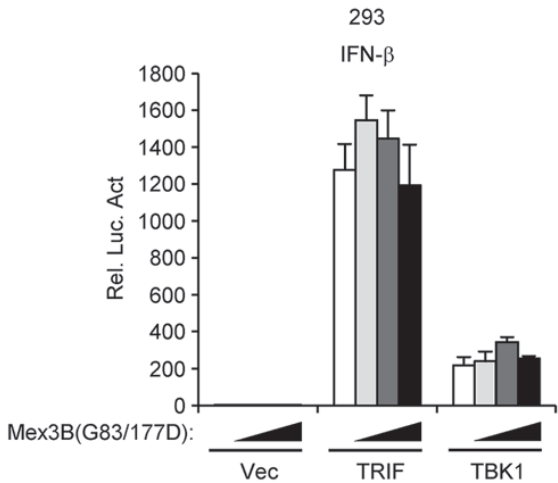

C

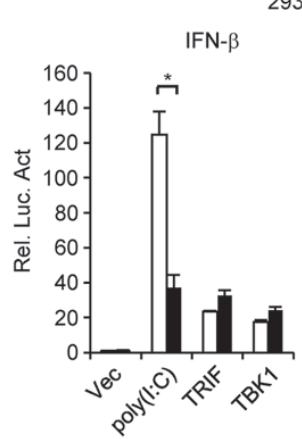

293-TLR3

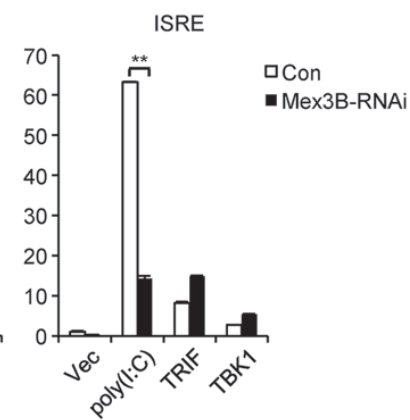

Figure 5 Mex3B regulates poly(I:C)-triggered signaling through TLR3. (A) Mex3B(G83/177D) inhibits poly(I:C)- but not TRIF-induced signaling. The 293 cells $\left(1 \times 10^{5}\right)$ were transfected with the indicated plasmids and increased amounts of a Mex3B plasmid. Twenty-four hours after transfection, cells were treated with poly(l:C) $(20 \mu \mathrm{g} / \mathrm{ml})$ for $6 \mathrm{~h}$ before luciferase assays were performed. (B) TLR3(C95/122A) inhibits poly(I:C)-induced, TLR3/Mex3B-mediated signaling. The experiments were similarly performed as in A. (C) Knockdown of Mex3B inhibits poly(I:C)- but not TRIF- or TBK1-mediated activation of the IFN- $\beta$ promoter. The 293-TLR3 cells $\left(1 \times 10^{5}\right)$ were transfected with the IFN- $\beta$ promoter reporter $(0.1 \mu \mathrm{g})$ and either a control or Mex3B-RNAi plasmid $(0.5 \mu \mathrm{g})$. Transfected cells were selected with puromycin $(1 \mu \mathrm{g} / \mathrm{ml})$ for $24 \mathrm{~h}$ followed by either treatment with poly $(\mathrm{l}: \mathrm{C})(20 \mu \mathrm{g} / \mathrm{ml})$ or retransfection with TRIF or TBK-1 plasmids $(0.1 \mu \mathrm{g})$. Luciferase assays were performed $6 \mathrm{~h}$ after treatment or $18 \mathrm{~h}$ after retransfection. Data are represented as mean \pm SEM. ${ }^{*} P<0.05,{ }^{* *} P<0.01$ (Student's $t$-test). (D) Effects of chloroquine on TLR3- and Mex3B-mediated signaling. The 293 cells $\left(1 \times 10^{5}\right)$ were transfected with the indicated plasmids $(0.1 \mu \mathrm{g}$ each) for $24 \mathrm{~h}$. The cells were pretreated with chloroquine for $30 \mathrm{~min}$, and then treated with poly $(\mathrm{l}: \mathrm{C})(20 \mu \mathrm{g}$ $/ \mathrm{ml}$ ) for $6 \mathrm{~h}$ before luciferase assays. 
scraggy and subfertile phenotypes of the $M e x 3 b^{-/-}$mice [29]. In our study, the body weight and general appearance of $M e \times 3 b^{-/}$mice showed no obvious abnormality but the number of descendants of $M e \times 3 b^{-1-}$ mice was $20 \%$ lower than that of wild-type mice. These minor discrepancies may be caused by the different gene knockout strategies used.

Several lines of evidence suggest that Mex3B acts as a coreceptor of TLR3. First, Mex3B and TLR3 colocalized in the endosomes, and they were associated with each other constitutively. In addition, Mex3B was associated with the adapter protein TRIF upon poly(I:C) stimulation. Second, overexpression of Mex3B promoted TLR3 processing, whereas knockdown of Mex3B destabilized TLR3. These results suggest that Mex3B has important roles in stabilizing TLR3 and facilitating its processing, which is required for its activation. Third, Mex3B is an RNA-binding protein, which enhanced the binding of TLR3 to the viral dsRNA analog poly(I:C). Fourth, Mex3B(G83/177D), a point mutant that lacks the RNA-binding activity, acted as a dominant-negative mutant to inhibit TLR3-mediated signaling, but had no marked inhibitory effects on activation of the IFN- $\beta$ promoter mediated by overexpression of TRIF and TBK1, which are downstream components of TLR3 signaling.

In conclusion, our studies have identified Mex3B as a coreceptor of TLR3, which is critically involved in TLR3-mediated innate immune and inflammatory responses (a working model is shown in Figure 8). Previously, it has been demonstrated that CD14 acts as a coreceptor of TLR4 in LPS-induced inflammatory responses [30]. In light of these and our findings, it is highly plausible that utilization of coreceptors may be a general strategy for TLR-mediated signaling and innate immune responses.

\section{Materials and Methods}

\footnotetext{
Mice

$M e x 3 b^{-1-}$ mice were generated by a conventional gene-targeting strategy. In the targeting vector, two exons of $M e x 3 b$ are flanked by two $\operatorname{lox} P$ sites and a neomycin-resistance gene cassette. The neomycin cassette served as the positive selection marker during the ES-targeting step. Successful targeting would lead to the deletion of all of the coding sequences. After electroporation of the Mex3b-targeting vector into embryonic stem cells $\left(129 \mathrm{~S}_{\mathrm{V}} /\right.$ $\mathrm{E}_{\mathrm{V}}$ ), G418 and gancyclovir double-resistant colonies were selected and screened by PCR. The selected Mex $3 b$ ES clones were injected into the blastocysts of C57BL/6 mice. Chimeric mice were mated with $\mathrm{C} 57 \mathrm{BL} / 6$ female mice to produce heterozygotes. The heterozygotes were interbred to produce homozygous mice. Mice and embryos were genotyped by PCR using the following primers: \#1-CTCCATGATCCGAGCCTCTC, \#2-GTGTAGGAGTGATGCTTGGG, \#3-CGCCTCCCCCAGCGATAGTGT-
}

CAGT, \#4-GACCCACCCCTTCCCAGCCTCTG. Amplification of the wild-type allele with primer $1 \#$ and $2 \#$ results in a 425 -bp fragment, and amplification of the knockout allele with primer \#3 and \#4 results in a 620-bp fragment. The primers used for qPCR analysis of murine Mex $3 \mathrm{~b}$ mRNA are as follows: ACCCAGTTCCGAACACGTCG (forward) and TGTTCTTGTTACGAGAGGCT (reverse). All animal experiments were performed in accordance with the Wuhan Institute of Virology animal care and use committee guidelines.

\section{Isolation of MEFs, BMDMs and DCs}

MEFs were prepared from day 13.5 embryos and cultured in DMEM containing 10\% FBS. Bone marrow cells were isolated from tibiae and femur of mice. For preparation of BMDMs, the bone marrow cells $\left(1 \times 10^{7}\right)$ were cultured in RPMI 1640 medium supplemented with 10\% FBS and conditioned medium from L929 cells for 3-5 days. For preparation of DCs, the bone marrow cells $\left(1 \times 10^{7}\right)$ were cultured in RPMI 1640 medium supplemented with $10 \%$ FBS, murine GM-CSF (10 ng/ml) and IL-4 (10 ng/ml) for 6-9 days.

The HCT116(Mex3B-3×Flag) knockin cell line was obtained according to previously reported genetic approach [31, 32]. The recombinant adeno-associated virus (rAAV) targeting vector contains a left 'arm' homologous to sequence upstream of the stop codon of Mex $3 b$ gene, a triple Flag epitope tag ( $3 \times$ Flag), a neomycin gene flanked by loxP sites and a right 'arm' homologous to sequence downstream of the stop codon of Mex3b gene. Targeting rAAV viruses were packaged in 293 cells. HCT116 cells were infected with targeting virus and selected for neomycin-resistant clones. We identified clones by genomic PCR and infected the correctly targeted clones with adenovirus expressing Cre recombinase to excise the neomycin gene cassette.

The 293 cells stably expressing TLR3 (293-TLR3) were generously provided by Katherine Fitzgerald (University of Massachusetts Medical School, USA) and Tom Maniatis (Harvard University, USA).

\section{Reagents and antibodies}

Poly(I:C), LPS, R837, PGN, chloroquine (Invivogen); TNF $\alpha$, IL-1 $\beta$ (R\&D Systems); D-galactosamine (Sigma); GM-CSF (peproTech); ELISA kit for murine IFN- $\beta$, TNF $\alpha$, IL-6 (Biolegend); dual-specific luciferase assay kit (Promega); EZ-link Psoralen-PEG $\mathrm{P}_{3}$-Biotin (Thermo); streptavidin agarose (Solulink); lysosome isolation kit (sigma); mouse monoclonal antibodies against Flag, $\beta$-actin (Sigma), HA (OriGene), phospho-IB $\alpha$ (Cell Signaling Technology), TLR3 (IMGENEX); rabbit monoclonal antibodies against TLR3, phospho-IRF3 (Cell Signaling Technology); rabbit polyclonal antibodies against IRF3 (Santa Cruz Biotechnology), TRIF (Cell Signaling Technology), TBK1 and phospho-TBK1(EPITOMICS), Flag (MBL); Alexa Fluor 555-conjugated goat anti-rabbit IgG antibody, Alexa Fluor 647-conjugated goat anti-mouse IgG antibody (Invitrogen) were purchased from the indicated manufacturers. Mouse antisera against human Mex3B were raised against recombinant human Mex3B fragments containing aa236-517 and aa1-517, respectively.

\section{Constructs}

IFN- $\beta$, ISRE and NF- $\kappa$ B luciferase reporter plasmids, mammalian expression plasmids for HA-, Flag-tagged TRIF and TBK1 
A

DC

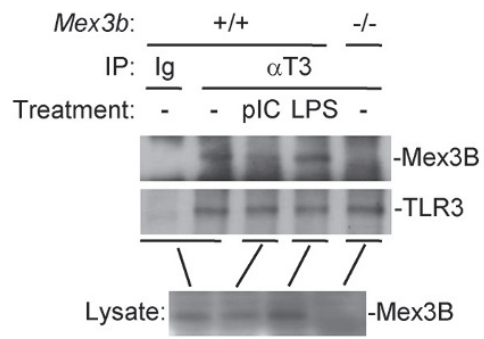

B

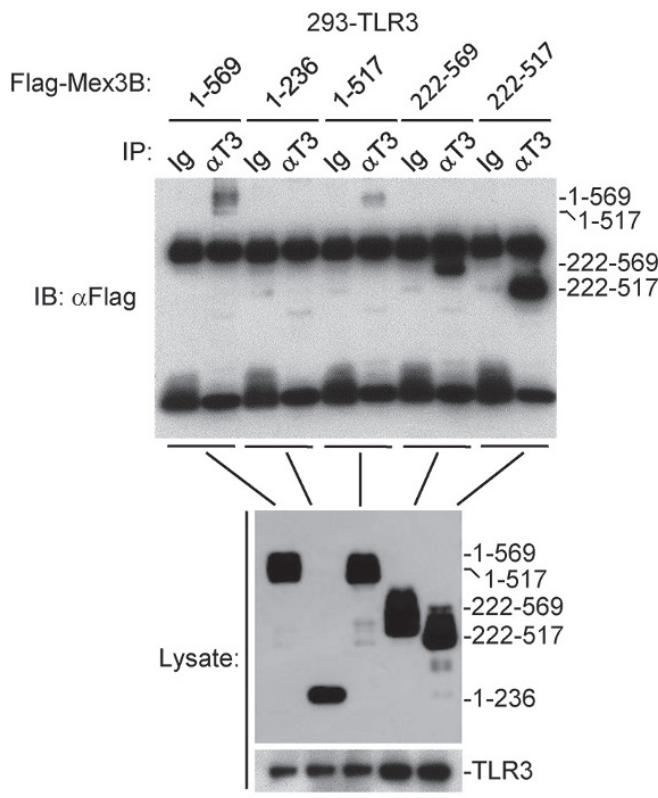

HCT116

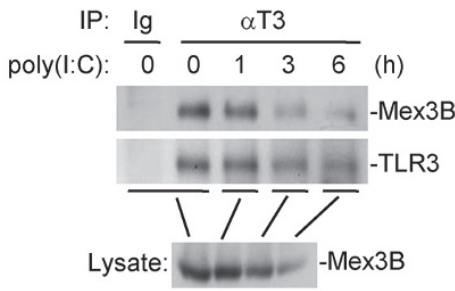

293

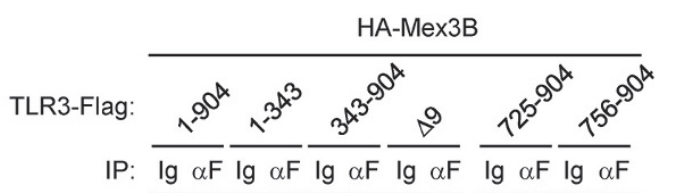

IB: $\alpha H A$

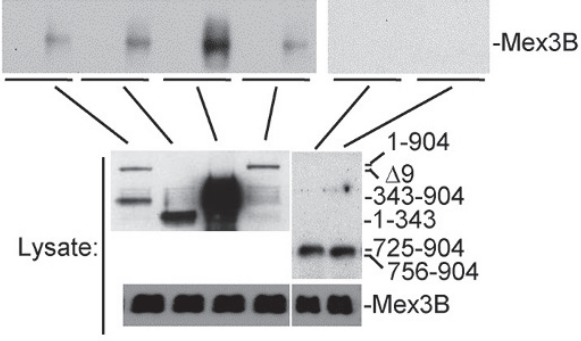

C

HCT116

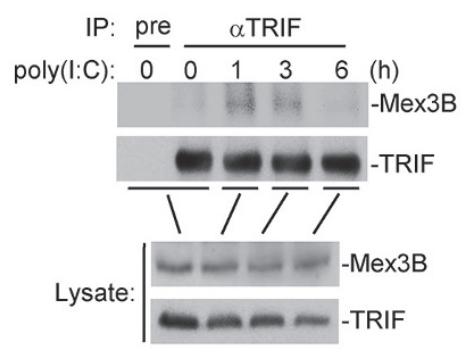

Figure 6 Mex3B is associated with TLR3 and facilitates the recruitment of TRIF upon poly(I:C) stimulation. (A) Mex3B interacts with TLR3. HCT116(Mex3B-3×Flag) cells $\left(1 \times 10^{8}\right)$, in which a cDNA encoding three copies of Flag tag was inserted immediately before the stop codon of Mex3b gene [32], or mouse DCs $\left(1 \times 10^{8}\right)$ were treated with poly $(\mathrm{l}: \mathrm{C})(20 \mu \mathrm{g} / \mathrm{ml})$ or LPS $(20$ $\mathrm{ng} / \mathrm{ml}$ ) for the indicated times. Coimmunoprecipitation and immunoblots were performed with the indicated antibodies. plC, poly (I:C). (B) Domain mapping of the Mex3B-TLR3 interaction. The 293-TLR3 cells $\left(2 \times 10^{6}\right)$ were transfected with either the full-length or the indicated Mex3B truncation plasmids $(5 \mu \mathrm{g})$. Coimmunoprecipitation and immunoblot were performed with the indicated antibodies. Ig, mouse IgG; $\alpha$ T3, anti-TLR3. (C) Mex3B interacts with TRIF upon poly(I:C) stimulation. HCT116 (Mex3B-3×Flag) cells $\left(1 \times 10^{8}\right)$ were left untreated or treated with poly $(\mathrm{l}: \mathrm{C})(20 \mu \mathrm{g} / \mathrm{ml})$ for the indicated times. Coimmunoprecipitation and immunoblots were performed with the indicated antibodies. 
A

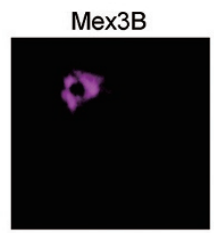

Mex3B

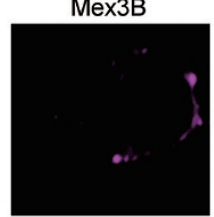

Mex3B
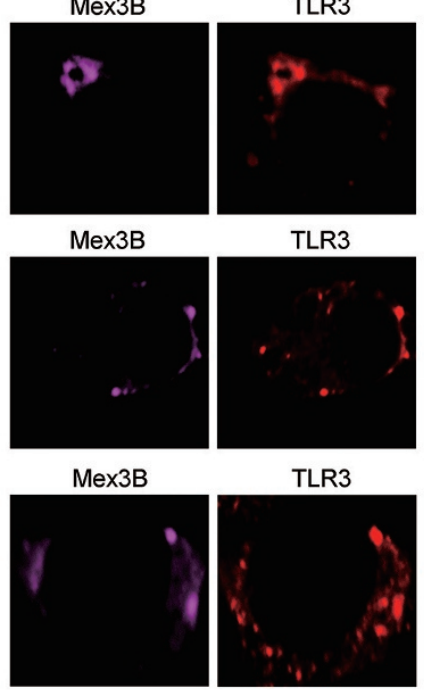

TLR3

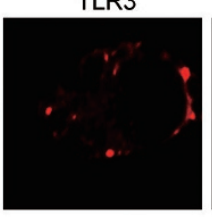

TLR3

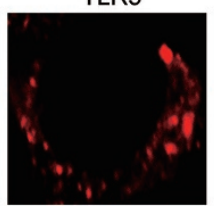

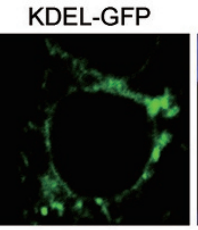

EEA1-GFP

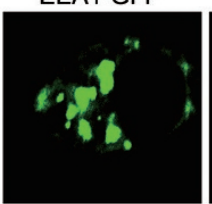

LAMP1-GFP

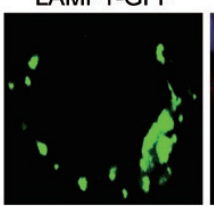

B

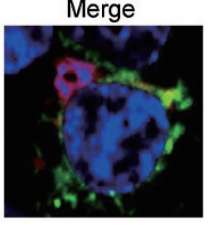

Merge

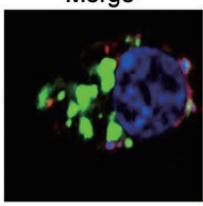

Merge

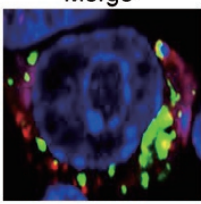

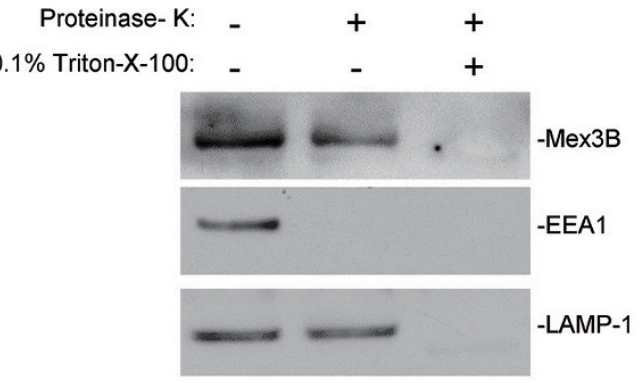

C

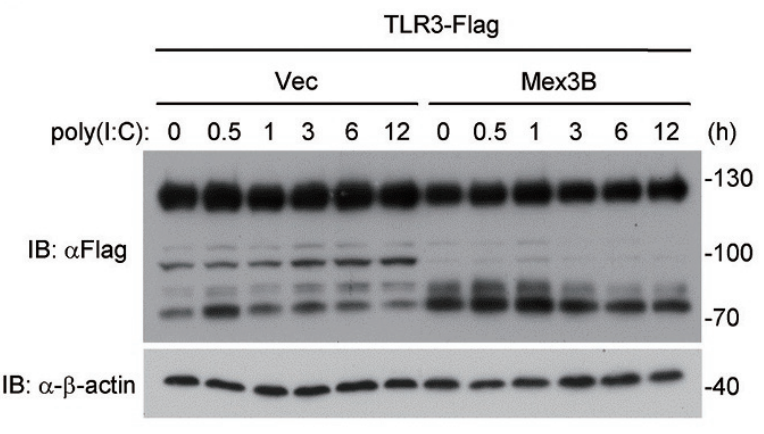

$\mathrm{E}$

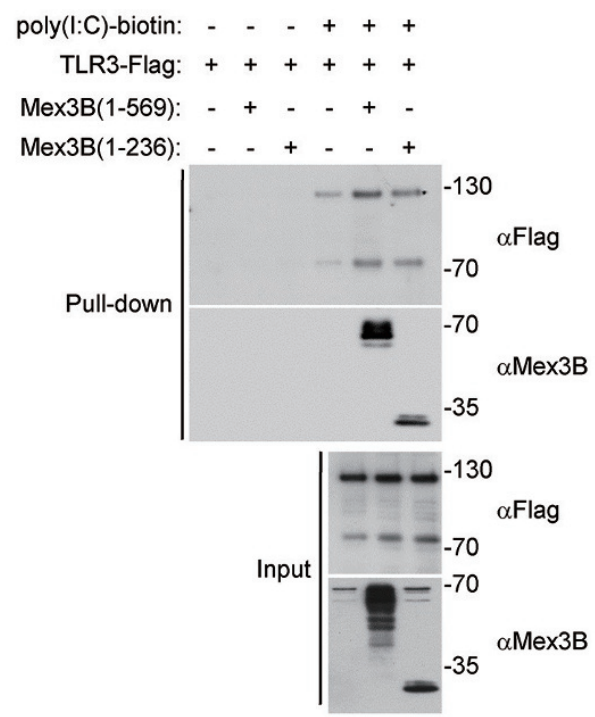

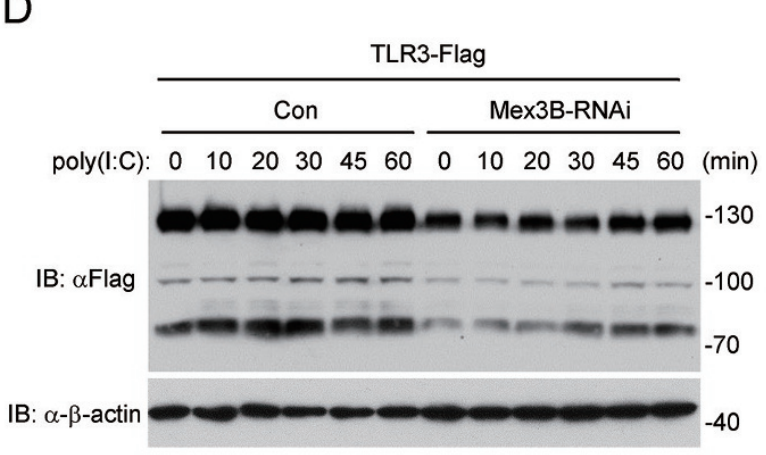

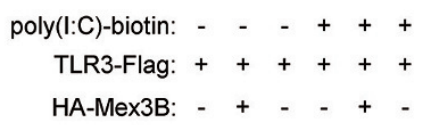

HA-Mex3B(G83/177D):

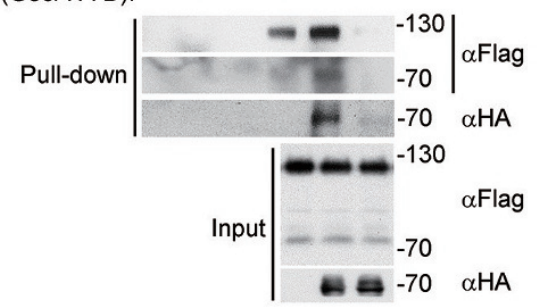


were previously described [33, 34]. Mammalian expression plasmids for TLR3 and Mex3B truncation, and point mutants were constructed by standard molecular biology techniques.

\section{Transfection and reporter assays}

The 293 cells $\left(1 \times 10^{5}\right)$ were seeded on 24 -well plates and transfected the next day by standard calcium phosphate precipitation method. HeLa and HCT116 cells were transfected by lipofectamine 2000. Empty control plasmid was added to ensure that each transfection receives the same amount of total DNA. To normalize transfection efficiency, $0.01 \mu \mathrm{g}$ of pRL-TK (Renilla luciferase) reporter plasmid was added to each transfection. Luciferase assays were performed using a dual-specific luciferase assay kit.

\section{RNA interference}

Double-strand oligonucleotides corresponding to the target sequences were cloned into the pSuper.Retro-RNAi plasmid (Oligoengine). The targeted sequences for human Mex3B mRNA were as follows: \#1-GCAAGAAGAGCGTGAACAT; \#2-GAGAGGAGATTGAGGCGCA; \#3-CAGCAGACGCACACGTACA; \#4-CGGCAAGGTTGTAAAATCA. The targeted sequences for the other three human Mex3s were as follows: GACCAACACCTACATCAAG (Mex3A); GGAAGTGGCTCTACAGATT (Mex3C); GCCATCCGAATATTCTCCT (Mex3D).

\section{In vitro pull-down assays}

Poly(I:C) was conjugated with biotin by UV (365-nm wavelength) cross-linking for $1 \mathrm{~h}$. The 293 cells transfected with the indicated plasmids were lysed in lysis buffer $(20 \mathrm{mM}$ Tris- $\mathrm{HCl}$, pH 6.0, $150 \mathrm{mM} \mathrm{NaCl}, 1 \mathrm{mM}$ EDTA, 1\% NP-40). Lysates were incubated with biotinylated-poly(I:C) for $1 \mathrm{~h}$ at $4{ }^{\circ} \mathrm{C}$ and then incubated with streptavidin agarose for another $2 \mathrm{~h}$ at $4{ }^{\circ} \mathrm{C}$. The beads were washed three times with lysis buffer and analyzed by immunoblot.

\section{Fluorescent confocal microscopy}

The 293 cells transfected with the indicated plasmids were stimulated or left untreated with poly(I:C) for $30 \mathrm{~min}$, fixed with $4 \%$ paraformaldehyde for $10 \mathrm{~min}$ and permeabilized with $0.1 \%$ Triton X-100 in PBS for 15 min on ice. The cells were blocked with $1 \%$ BSA in PBS and stained with the indicated primary and secondary antibodies for $1 \mathrm{~h}$. The nuclei were stained with DAPI.
The cells were observed with a Nikon confocal microscope under a 60 oil objective.

\section{Poly(I:C)-induced production of cytokines in mice}

Age- and sex-matched Mex $3 b^{+++}$mice and $M e x 3 b^{-/-}$mice were injected i.p. with poly(I:C) $(2 \mu \mathrm{g} / \mathrm{g}$ body weight $)$ plus D-galactosamine $(0.25 \mathrm{mg} / \mathrm{g}$ body weight $)$. The survival of the injected mice was monitored every $12 \mathrm{~h}$. The blood was collected $2 \mathrm{~h}$ after injection, and the concentrations of IFN- $\beta$, TNF $\alpha$ and IL- 6 were measured by ELISA.

\section{$q P C R$}

Total RNA was isolated from cells using Trizol reagent (TAKARA, Japan) and subjected to qPCR analysis to measure expression of mRNA. Gene-specific primer sequences used for qPCR were as follows: human Ifnb1, TTGTTGAGAACCTCCTGGCT, TGACTATGGTCCAGGCACAG; ISG56, TCATCAGGTCAAGGATAGTC, CCACACTGTATTTGGTGTCTAGG; human Tnfa, GCCGCATCGCCGTCTCCTAC, CCTCAGCCCCCTCTGGGGTC; human Ikba, CGGGCTGAAGAAGGAGCGGC, ACGAGTCCCCGTCCTCGGTG; human Gapdh, GAGTCAACGGATTTGGTCGT, GACAAGCTTCCCGTTCTCAG; mouse Ifnb, TCCTGCTGTGCTTCTCCACCACA, AAGTCCGCCCTGTAGGTGAGGTT; mouse Tnfa, GGTGATCGGTCCCCAAAGGGATGA, TGGTTTGCTACGACGTGGGCT; mouse $I k b a$, AACGCTCAGGAGCCCTGCAAT, ACCCTGTTGACATCAGCCCCACA; mouse Gapdh, ACGGCCGCATCTTCTTGTGCA, ACGGCCAAATCCGTTCACACC.

\section{Coimmunoprecipitation and immunoblot analysis}

Transfected 293 cells were lysed in $1 \mathrm{ml}$ lysis buffer $(20 \mathrm{mM}$ Tris $\cdot \mathrm{HCl}, \mathrm{pH}$ 7.4, $150 \mathrm{mM} \mathrm{NaCl}, 1 \mathrm{mM}$ EDTA, $1 \%$ Nonidet P-40, $10 \mu \mathrm{g} / \mathrm{ml}$ aprotinin, $10 \mu \mathrm{g} / \mathrm{ml}$ leupeptin and $1 \mathrm{mM}$ phenylmethylsulfonyl fluoride). For each immunoprecipitation, $0.8 \mathrm{ml}$ of cell lysate was incubated with $0.5 \mu \mathrm{g}$ of the indicated antibody and $25 \mu \mathrm{l}$ of $50 \%$ slurry of GammaBind G Plus-Sepharose (Amersham Biosciences) at $4{ }^{\circ} \mathrm{C}$ for $2 \mathrm{~h}$. The Sepharose beads were then washed three times with $1 \mathrm{ml}$ of lysis buffer containing $500 \mathrm{mM} \mathrm{NaCl}$. The precipitates were analyzed by standard immunoblot procedures.

For endogenous coimmunoprecipitation experiments, HCT116 cells or DCs $\left(1 \times 10^{8}\right)$ were treated with LPS or poly(I:C) for the

Figure 7 Mex3B colocalizes with TLR3 in the endosome and promotes the processing, stability and ligand binding of TLR3. (A) Mex3B colocalizes with TLR3 in the endosomes. The 293 cells $\left(1 \times 10^{5}\right)$ were cotransfected with Mex3B-HA and TLR3Flag plus KDEL-GFP (ER marker), EEA1-GFP (early endosome marker) or LAMP-1-GFP (lysosome marker). Twenty hours after transfection, cells were fixed with $4 \%$ paraformaldehyde, stained with anti-Flag and anti-HA antibodies, and subjected to confocal microscopy. (B) Mex3B is sorted into the lumen of endosomes. HCT116 (Mex3B-3×Flag) cells $\left(4 \times 10^{8}\right)$ were collected and washed twice with ice-cold PBS. Endosome/lysosome fractions were isolated and either left untreated, treated with proteinase $\mathrm{K}(5 \mathrm{ng} / \mathrm{ml})$ or treated with proteinase plus $0.1 \%$ Triton X-100 for $15 \mathrm{~min}$ at room temperature. The samples were then analyzed with the indicated antibodies. (C) Overexpression of Mex3B increases the abundance of processed C-terminal fragment of TLR3. The 293 cells $\left(2 \times 10^{5}\right)$ were transfected with the indicated plasmids. Twenty-four hours after transfection, cells were treated with poly $(\mathrm{l}: \mathrm{C})(20 \mu \mathrm{g} / \mathrm{ml})$ for the indicated times before immunoblot. The relative amount of total TLR3 was quantitated by the Bio-Rad Quantity One program. (D) Knockdown of Mex3B affects the stability of TLR3. The 293 cells ( $2 \times$ $\left.10^{5}\right)$ were transfected with TLR3 $(0.5 \mu \mathrm{g})$ and Mex3B-RNAi plasmid $(1 \mu \mathrm{g})$. Transfected cells were selected with puromycin $(1 \mu \mathrm{g} / \mathrm{ml})$ for $24 \mathrm{~h}$ and then treated with poly $(\mathrm{l}: \mathrm{C})$ for the indicated times before immunoblot. (E) Mex3B enhances binding of poly(I:C) to TLR3. The 293 cells $\left(2 \times 10^{6}\right)$ were transfected with the indicated plasmids $(5 \mu \mathrm{g}$ each). Cell lysates were mixed at $1: 1$ ratio as indicated and incubated with biotinylated-poly $(\mathrm{l}: \mathrm{C})$ for $1 \mathrm{~h}$ before pull-down assays were performed with streptavidin agarose. Precipitates and cell lysates were analyzed by immunoblot with the indicated antibodies. 


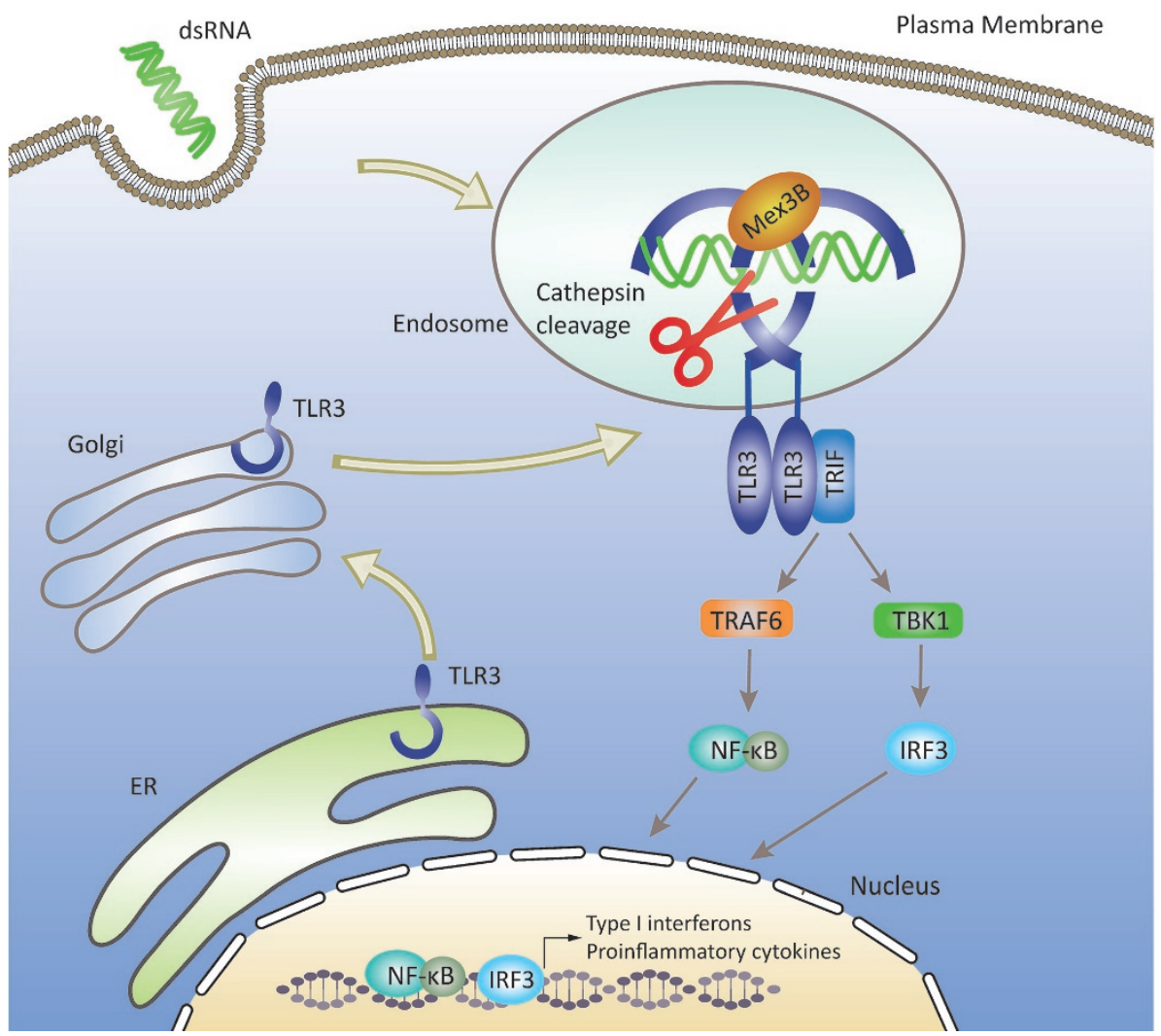

Figure 8 A working model on the involvement of Mex3B in TLR3-mediated signaling. Upon viral infection, TLR3 transports from the ER to endosomes where it is proteolytically cleaved, resulting in the formation of a very stable "cleaved/associated" TLR3 that represents the primary form of the signaling receptor. The RNA-binding protein Mex3B localizes in the lumen of endosomes, functions as a coreceptor of TLR3 by promoting ligand binding and proteolytic processing of TLR3, resulting in full activation of TLR3.

indicated times or left untreated. The coimmunoprecipitation and immunoblot experiments were performed as described above.

\section{Proteinase $K$ protection assays}

Proteinase $\mathrm{K}$ protection assays were performed as described by the manufacturer. HCT116 (Mex3B-3×Flag) cells $\left(4 \times 10^{8}\right)$ were collected and washed twice with ice-cold PBS. The endosome/ lysosome fractions were isolated from cells by calcium precipitation, and left untreated, treated with $5 \mathrm{ng} / \mathrm{ml}$ proteinase $\mathrm{K}$ or treated with proteinase $\mathrm{K}$ plus $0.1 \%$ Triton $\mathrm{X}-100$ for $15 \mathrm{~min}$ at room temperature. The samples were then mixed with $2 \times$ SDS loading buffer and analyzed by western blot.

\section{Acknowledgments}

This study was supported by the National Science Fund for Distinguished Young Scholars (31425010), the National Natural Science Foundation of China (31321001, 31270932 and 31400743), the Ministry of Science and Technology of China (2014CB542603 and 2015CB554302) and the 10000 Talent Program. We thank
Ding Gao and Xue-Fang An from the Core Facility and Technical Support of Wuhan Institute of Virology for their help with confocal microscopy and animal infection experiments, respectively.

\section{Author Contributions}

YY and Y-Y W designed the study; YY, S-Y W, Z-F H, H-M Z, B-R Y and W-W L performed the experiments; YY and Y-Y W analyzed the data; YY and Y-Y W wrote the paper.

\section{Competing Financial Interests}

The authors declare no conflict of interest.

\section{References}

1 Kawai T, Akira S. Toll-like receptors and their crosstalk with other innate receptors in infection and immunity. Immunity 2011; 34:637-650.

2 Jin MS, Lee JO. Structures of the toll-like receptor family and its ligand complexes. Immunity 2008; 29:182-191.

3 Blasius AL, Beutler B. Intracellular toll-like receptors. Immu- 
nity 2010; 32:305-315.

4 McGettrick AF, O'Neill LA. Localisation and trafficking of Toll-like receptors: an important mode of regulation. Curr Opin Immunol 2010; 22:20-27.

5 Matsumoto M, Funami K, Tanabe M, et al. Subcellular localization of Toll-like receptor 3 in human dendritic cells. $J$ Immunol 2003; 171:3154-3162.

6 Qi R, Hoose S, Schreiter J, et al. Secretion of the human Tolllike receptor 3 ectodomain is affected by single nucleotide polymorphisms and regulated by Unc93b1. J Biol Chem 2010; 285:36635-36644.

7 Garcia-Cattaneo A, Gobert FX, Muller M, et al. Cleavage of Toll-like receptor 3 by cathepsins $\mathrm{B}$ and $\mathrm{H}$ is essential for signaling. Proc Natl Acad Sci USA 2012; 109:9053-9058.

8 Qi R, Singh D, Kao CC. Proteolytic processing regulates Tolllike receptor 3 stability and endosomal localization. $J$ Biol Chem 2012; 287:32617-32629.

9 Pohar J, Pirher N, Bencina M, et al. The role of UNC93B1 protein in surface localization of TLR3 receptor and in cell priming to nucleic acid agonists. $J$ Biol Chem 2013; 288:442454.

10 Toscano F, Estornes Y, Virard F, et al. Cleaved/associated TLR3 represents the primary form of the signaling receptor. $J$ Immunol 2013; 190:764-773.

11 Murakami Y, Fukui R, Motoi Y, et al. Roles of the cleaved N-terminal TLR3 fragment and cell surface TLR3 in double-stranded RNA sensing. J Immunol 2014; 193:5208-5217.

12 Bell JK, Botos I, Hall PR, et al. The molecular structure of the Toll-like receptor 3 ligand-binding domain. Proc Natl Acad Sci USA 2005; 102:10976-10980.

13 Choe J, Kelker MS, Wilson IA. Crystal structure of human toll-like receptor 3 (TLR3) ectodomain. Science 2005; 309:581-585.

14 Liu L, Botos I, Wang Y, et al. Structural basis of toll-like receptor 3 signaling with double-stranded RNA. Science 2008; 320:379-381.

15 Lee HK, Dunzendorfer S, Soldau K, et al. Double-stranded RNA-mediated TLR3 activation is enhanced by CD14. Immunity 2006; 24:153-163.

16 Itoh K, Watanabe A, Funami K, et al. The clathrin-mediated endocytic pathway participates in dsRNA-induced IFN-beta production. J Immunol 2008; 181:5522-5529.

17 Limmon GV, Arredouani M, McCann KL, et al. Scavenger receptor class-A is a novel cell surface receptor for double-stranded RNA. FASEB J 2008; 22:159-167.

18 Buchet-Poyau K, Courchet J, Le Hir H, et al. Identification and characterization of human Mex-3 proteins, a novel family of evolutionarily conserved RNA-binding proteins differentially localized to processing bodies. Nucleic Acids Res 2007; 35:1289-1300.

19 Pereira B, Le Borgne M, Chartier NT, et al. MEX-3 proteins: recent insights on novel post-transcriptional regulators. Trends Biochem Sci 2013; 38:477-479.

20 Kuniyoshi K, Takeuchi O, Pandey S, et al. Pivotal role of RNA-binding E3 ubiquitin ligase MEX3C in RIG-I-mediated antiviral innate immunity. Proc Natl Acad Sci USA 2014; 111:5646-5651.

21 Zhang SY, Jouanguy E, Ugolini S, et al. TLR3 deficiency in patients with herpes simplex encephalitis. Science 2007;
317:1522-1527.

22 Guo Y, Audry M, Ciancanelli M, et al. Herpes simplex virus encephalitis in a patient with complete TLR3 deficiency: TLR3 is otherwise redundant in protective immunity. $J$ Exp Med 2011; 208:2083-2098.

23 Courchet J, Buchet-Poyau K, Potemski A, et al. Interaction with 14-3-3 adaptors regulates the sorting of hMex-3B RNA-binding protein to distinct classes of RNA granules. $J$ Biol Chem 2008; 283:32131-32142.

24 de Bouteiller O, Merck E, Hasan UA, et al. Recognition of double-stranded RNA by human toll-like receptor 3 and downstream receptor signaling requires multimerization and an acidic pH. J Biol Chem 2005; 280:38133-38145.

25 Johnsen IB, Nguyen TT, Ringdal M, et al. Toll-like receptor 3 associates with $\mathrm{c}-\mathrm{Src}$ tyrosine kinase on endosomes to initiate antiviral signaling. EMBO J 2006; 25:3335-3346.

$26 \mathrm{Li} \mathrm{XD,} \mathrm{Wu} \mathrm{J,} \mathrm{Gao} \mathrm{D,} \mathrm{et} \mathrm{al.} \mathrm{Pivotal} \mathrm{roles} \mathrm{of} \mathrm{cGAS-cGAMP}$ signaling in antiviral defense and immune adjuvant effects. Science 2013; 341:1390-1394.

27 Pagano JM, Farley BM, Essien KI, et al. RNA recognition by the embryonic cell fate determinant and germline totipotency factor MEX-3. Proc Natl Acad Sci USA 2009; 106:2025220257.

28 Pereira B, Sousa S, Barros R, et al. CDX2 regulation by the RNA-binding protein MEX3A: impact on intestinal differentiation and stemness. Nucleic Acids Res 2013; 41:3986-3999.

29 Le Borgne M, Chartier N, Buchet-Poyau K, et al. The RNA-binding protein Mex3b regulates the spatial organization of the Rap1 pathway. Development 2014; 141:2096-2107.

30 Wright SD, Ramos RA, Tobias PS, et al. CD14, a receptor for complexes of lipopolysaccharide (LPS) and LPS binding protein. Science 1990; 249:1431-1433.

31 Li Y, Chen R, Zhou Q, et al. LSm14A is a processing body-associated sensor of viral nucleic acids that initiates cellular antiviral response in the early phase of viral infection. Proc Natl Acad Sci USA 2012; 109:11770-11775.

32 Zhang X, Guo C, Chen Y, et al. Epitope tagging of endogenous proteins for genome-wide ChIP-chip studies. Nat Methods 2008; 5:163-165.

33 Yang Y, Liao B, Wang S, et al. E3 ligase WWP2 negatively regulates TLR3-mediated innate immune response by targeting TRIF for ubiquitination and degradation. Proc Natl Acad Sci USA 2013; 110:5115-5120.

34 Han KJ, Yang Y, Xu LG, et al. Analysis of a TIR-less splice variant of TRIF reveals an unexpected mechanism of TLR3-mediated signaling. J Biol Chem 2010; 285:1254312550 .

(Supplementary information is linked to the online version of the paper on the Cell Research website.)

(c) $(1)(5)$ This work is licensed under a Creative Commons Attribution-NonCommercial-NoDerivs 4.0 Unported License. The images or other third party material in this article are included in the article's Creative Commons license, unless indicated otherwise in the credit line; if thematerial is not included under the Creative Commons license, users will need to obtain permission from the license holder to reproduce the material. To view a copy of this license, visit http://creativecommons.org/licenses/by-nc-nd/4.0/ 